\title{
El ahorro minorista de la banca privada española, 1900-1935*
}

\author{
- Ángel Pascual Martínez Soto \\ Universidad de Murcia \\ - ANDrÉs Hoyo APARICIO \\ Universidad de Cantabria
}

\section{Introducción}

A lo largo del primer tercio de siglo Xx, la capacidad de ahorro de las clases populares y medias, tanto urbanas como rurales, creció de manera apreciable en consonancia con el ciclo económico que se ha denominado la edad de plata de la economía española. La mejora de los salarios, especialmente entre 1900-1915 y 1923-1929, aumentó las posibilidades de lograr ciertos excedentes de renta en estos grupos, y con ello se incrementó la propensión a ahorrar como forma primaria de previsión.

Con el nuevo siglo, la banca privada inició un proceso de expansión, que se acentuó durante el período de la Primera Guerra Mundial y que, tras un paréntesis de crisis locales en los años centrales de la década de los veinte, continuó su desarrollo hasta $1930 .{ }^{1}$ En este contexto de expansión territorial y de negocios, la mayoría de las entidades pusieron en práctica estrategias y productos para penetrar en el creciente mercado minorista del ahorro, que hasta comienzos de ese nuevo siglo había estado acaparado por las cajas de ahorros benéficas.

Este sector de las cajas benéficas cuenta con numerosos estudios de conjunto, de los que citaremos solo los más recientes. ${ }^{2}$ También disponemos de estudios regionales que detallan la evolución de estas entidades y su aporta-

* Este texto es resultado del Proyecto de investigación APIE 3/2015-2017, dentro de la línea estratégica del Santander Financial Institute (SANFI) de la Fundación UCEIF.

1. Tedde (1974); Roldán y García Delgado (1973), Muñoz (1978); Belford (1979); Tortella y Palafox (1983); Martín Aceña (1985 y 2011).

2. Martínez Soto (2000 y 2003); Martínez Soto y Cuevas Casaña (2004); Martínez Soto, Cuevas y Hoyo (2005); Comín (2007, 2008 y 2011). 
ción a la economía de sus respectivas regiones; ${ }^{3}$ incluso la revista Papeles de Economía Española publicó varios números monográficos en los años 2003 y 2005. En todas estas aportaciones las series del ahorro popular para los siglos XIX y XX están bien delimitadas y depuradas. Sin embargo, para el ahorro captado por la banca privada a través de sus propias cajas de ahorro solo disponemos de una primera aproximación realizada por Martínez Soto y Cuevas Casaña, que utilizaron fundamentalmente la serie que realizó el Instituto Nacional de Estadística. ${ }^{4}$

El trabajo que hemos elaborado se enmarca en el contexto competitivo entre las cajas de ahorros y la banca privada por el control del segmento minorista del mercado financiero español. Para mejorar el conocimiento de la rivalidad comercial entre los dos tipos de entidades financieras en el referido segmento, debemos fijar con mayor exactitud la cuota de mercado que fue logrando la banca privada, aspecto escasamente estudiado hasta la fecha. En nuestro país, desde una perspectiva histórica, el estudio de la competencia entre los bancos privados y las cajas de ahorros en el sector financiero minorista ha recibido poca atención; tan solo contamos con referencias importantes en el trabajo de Comín (2008) y en el de Maixé-Altés (2010). Fuera de nuestra historiografía ha ocurrido lo mismo, pues el principal foco de atención se ha centrado en analizar exclusivamente la competencia entre bancos. Una excepción han sido los trabajos de Emmons y Schmid (2000a y 2000b), que incluyeron en sus análisis de concurrencia competitiva en el mercado financiero otras instituciones no estrictamente bancarias, como fueron las cooperativas de ahorro y crédito. Sus estudios han permitido constatar como las empresas financieras pueden llegar a alcanzar mayores cuotas de mercado simplemente por el hecho de que sus costos sean más bajos, y esta es la razón fundamental para comprender por qué las cooperativas de ahorro y crédito compitieron directamente, con bastante éxito, en los mercados locales de depósitos domésticos de Estados Unidos.

El principal propósito de este trabajo es elaborar una nueva serie de cuenta «caja de ahorros» de los bancos privados españoles para el período 19001935, tratando de corregir los errores en los que incurren las fuentes hasta ahora disponibles. Con tal finalidad, en un primer apartado, se explica el método que hemos seguido para construir la nueva serie y las dificultades que hemos tenido que afrontar. A continuación, se presenta la serie y se muestran las diferencias con las hasta ahora disponibles, explicando sus ciclos de variación en función de la situación financiera del país y de los condicionantes institucionales que afectaron a la banca. En un segundo apartado se aborda la

3. Muñoz Ortega (1997); Sudrià y Nadal (1983); Maixé (2003); Titos (2003); Valdaliso (2007). Para una relación más completa, véase Martín Aceña y Pons (2005), pp. 674-675.

4. Martínez Soto y Cuevas Casaña (2004). 
situación de la banca privada respecto al «ahorro popular», tratando el proceso de competencia con las cajas de ahorros benéficas por el tramo minorista del mercado financiero. Con tal motivo, se presenta un estudio sobre la sectorización del ahorro popular en la propia banca (bancos nacionales, regionales y locales, banca por regiones) para poder entender mejor este proceso. Finalmente, ofrecemos unas conclusiones que fijan la atención en los puntos clave del trabajo.

\section{La banca privada ante el ahorro popular. Nueva serie «caja de ahorros» de los bancos, 1900-1935}

En medio del malestar financiero a que dio paso la suspensión de pagos y posterior quiebra del Banco de Barcelona, la revista mensual Publicaciones de Actualidad, fundada en agosto de 1921 y dirigida por el periodista Antonio Rodríguez López de Arco, concedió en más de una ocasión espacio a la denuncia y a la reflexión sobre las maneras de articular formas de control que «acabara con los abusos, previniendo los engaños a tiempo» que resultaban de una «conspiración de silencio» que rodeaba toda información contable de la actividad bancaria. En su segundo número, se publicaba un artículo en el que se denunciaba con vehemencia «el desenfado con que los bancos redactan ordinariamente sus balances», y que se explicaba por la circunstancia de la escasa transparencia que practicaban sus directivos ante su masa social y ante el Estado, en este caso para rehuir el control fiscal. ${ }^{5}$ Este oscurantismo llevaba al articulista a interrogarse, no sin ironía, sobre «¿cuáles son los bancos que nos hacen saber en sus balances qué parte del activo es realizable y qué parte no lo es, el detalle de la cartera, si el papel comercial que contenga es descontable y en qué proporción, si los títulos y valores son negociables y cuál es su valor y su naturaleza?», concluyendo con la constatación de que «las memorias leídas en las juntas generales de accionistas no tienen ninguna significación real desde el punto de vista de sus intereses, pues no contienen más que lo que es materialmente imposible callar».

Sin embargo, la revelación de información a través de la publicación de los estados contables fue ya considerada en el siglo XIX un bien público. Y a este interés general se apeló, con cierta frecuencia, en varios momentos del intenso debate que tuvo lugar en las Cortes Constituyentes del Bienio Progre-

5. «(...) las oligarquías que gobiernan los Bancos no dan cuenta de su situación y de sus operaciones al Estado porque los Bancos se consideran empresas privadas que no han de rendir cuenta más que a ellas mismas; pero tampoco dan cuenta a los accionistas para no divulgar sus negocios a los competidores, para rehuir la acción fiscal del Estado», en «La opinión púbica y las cuestiones financieras. Sobre la organización de los bancos y su funcionamiento», $P u$ blicaciones de Actualidad. Revista mensual de Hacienda, Banca e Industria, vol., 2, 1921, pp. 5-8. 
sista (julio de 1854-julio de 1856) a propósito de la necesidad de superar la restrictiva legislación vigente desde 1848 y a favor de una mayor libertad para el establecimiento de bancos. La Ley de Bancos de Emisión que, finalmente, se aprobó el 28 de enero de 1856 disponía, precisamente, en su artículo 21, la obligación de publicar los balances mensuales en la Gaceta de Madrid. Pero a pesar de este compromiso, Mercedes Bernal Llorens ha constatado la relación positiva que hubo entre la frecuencia de publicaciones por parte de los establecimientos bancarios y la particular situación financiera de cada uno de ellos, de tal modo que, en épocas de dificultad económica, el precepto de publicidad no siempre se cumplía. ${ }^{6}$ Tampoco llegó a concretarse el último párrafo del citado artículo en lo referente a que «los estados de situación habrían de emitirse en la forma prescrita por el Ministerio de Hacienda», y que sugiere que en el ánimo del legislador estuvo el deseo de normalizar los formatos presentados. ${ }^{7}$ De este modo, hasta la Ley de Ordenación Bancaria de 29 de diciembre de 1921, impulsada por Francesc Cambó en su etapa de ministro de Hacienda en el Gobierno de Antonio Maura, los bancos fueron en todo momento libres de presentar sus propios modelos de balance.

Esta falta de homogeneidad transversal y temporal en la presentación de los estados contables de los bancos, en la que incluso a veces incurría una misma sociedad, junto con el incumplimiento de los requisitos de información pública, dificulta enormemente el análisis de la evolución de la estructura patrimonial, sobre todo, como se han hecho eco de ello Bernal Llorens y Sánchez Ballesta, cuando lo que se pretende es construir indicadores individuales para cada entidad que sean comparables con el resto de los bancos. ${ }^{8}$ El estudio de la evolución de la caja de ahorros de los bancos privados tampoco escapa a esta serie de inconvenientes. Ello explica, así, los distintos perfiles que se observan en la proyección temporal de este tipo de cuenta según la fuente informativa que la sustente. Tal evidencia es la que se ha querido reflejar en el gráfico 1.

En el gráfico 1 se representa la evolución de la cuenta «caja de ahorros» de los bancos privados españoles según la información que suministran los resúmenes generales anuales que publicaban el Anuario Estadístico de España (INE), Anuario Financiero del Banco de Vizcaya (Vizcaya), Anuario Financiero de Bilbao (Bilbao) y el Anuario Financiero y de Sociedades Anónimas de España (España). Como puede fácilmente comprobarse, las disparidades son muy apreciables, y para algunos años, muy llamativas. Varias son las razones que explican tales diferencias. Unas son el resultado, como antes se decía, de la confusión que ocasiona la falta de homogeneidad en la presentación de los estados contables. En este caso hemos comprobado como esta cuenta, «caja de aho-

6. Bernal Llorens (2004); Bernal Llorens y Sánchez Ballesta (2016), pp. 111-113.

7. Pérez García (1991), pp. 87-91.

8. Bernal Llorens y Sánchez Ballesta (2007), pp. 45-47. 
GRÁFICO 1 - Banca privada española, 1900-1935. Distintas estimaciones de la cuenta «caja de ahorros» (en millones de pesetas)

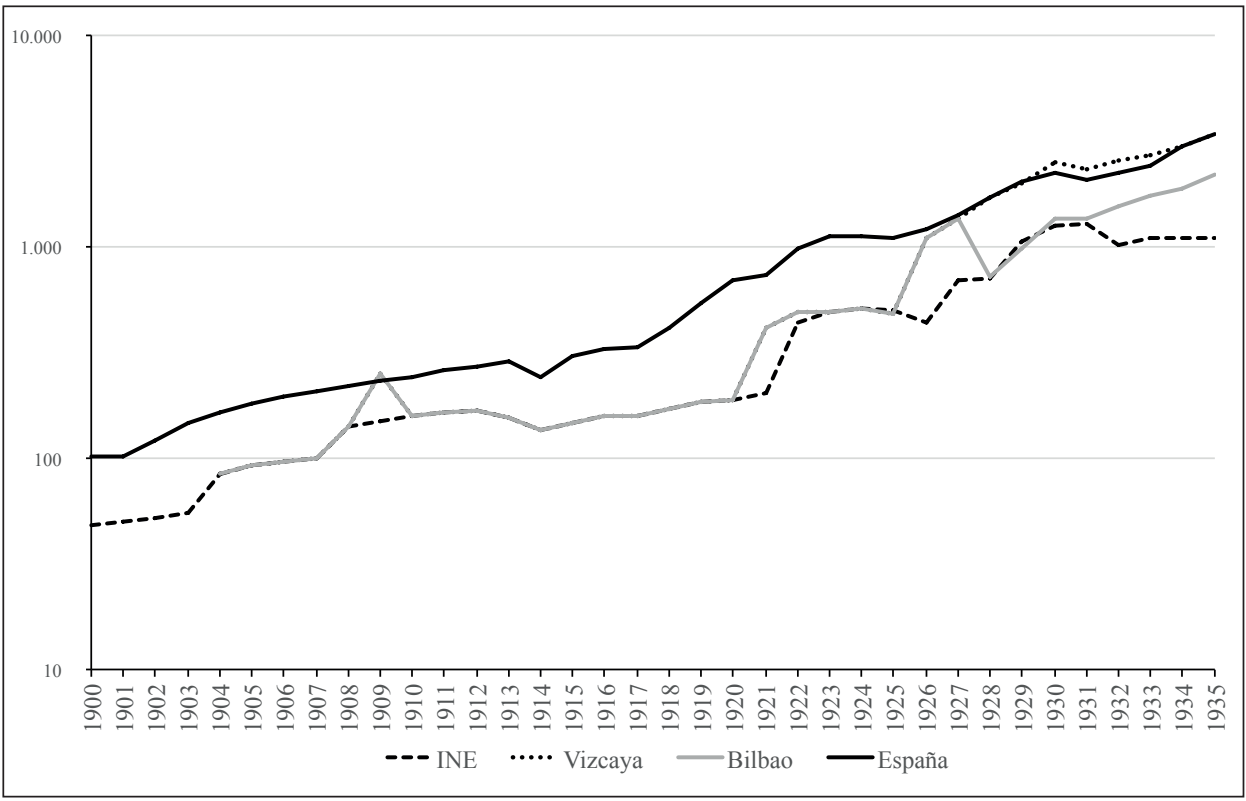

Fuente: Anuario Financiero y de Valores Mobiliarios, 1916-1917; Anuario Financiero y de Sociedades Anónimas de España, 1918-1940; Anuario Financiero de Bilbao, 1917-1936; Anuario Financiero del Banco de Vizcaya, 1917-1941; Anuario Estadístico de España, 1912-1936.

rros», a veces se presentaba bajo distintas rúbricas que cambiaban con el paso del tiempo (imposiciones, imposiciones de ahorro, caja de economías, cuenta de ahorro, cuentas de la clase obrera, acreedores hasta el plazo de un mes).

Las disparidades contables que se reflejan en las fuentes precitadas obedecen también a la circunstancia de que bajo esta misma cuenta se agregaban con frecuencia los saldos de todo tipo de depósitos de ahorro suscritos a distintos plazos. En la explicación de estas diferencias tampoco es menor la costumbre de, ante la falta de datos de uno o varios bancos en un año determinado, incluir la cifra del año inmediatamente anterior del que se disponía de información, sin corregirse esta anotación, una vez que se producía de la manera descrita, en los resúmenes anuales sucesivos. Finalmente, como explicación de estas discrepancias, tampoco debe minusvalorarse la que debe atribuirse al número de bancos que se incluían en los citados resúmenes anuales. Estos sí contenían los bancos nacionales y regionales que en su balance de pasivo figuraba el concepto «caja de ahorros» o «acreedores hasta el plazo de un mes», pero con frecuencia en la relación de algunos años quedaban fuera otros bancos locales que hemos comprobado que sí contaban, también, con una caja de ahorros. 
Todo lo que acabamos de describir ha tenido importantes consecuencias a la hora de estudiar la evolución de los saldos de la caja de ahorros de bancos, pues en función de la fuente que sustente los datos empleados, los resultados proyectados en el tiempo ofrecen perfiles sensiblemente diferentes. Por esta importante razón en este apartado queremos presentar una nueva serie «caja de ahorros» de bancos privados (saldos de las cuentas de ahorro a plazos menores de un mes) $)^{9}$ en la que se ha corregido en una alta proporción los inconvenientes que han dado lugar, por las razones antes señaladas, a las desviaciones observadas en las series que se han presentado (gráfico 1).

Pero antes de pasar a comentar las fuentes empleadas y la manera en que a partir de estas hemos confeccionado la nueva serie, detengámonos un momento en conocer cómo era la estructura del pasivo clientes ${ }^{10}$ por sectores de la banca privada en España. Para ello utilizamos como referencia los datos del año 1931, pues la fuente en la que nos apoyamos ofrece para ese año una información panorámica muy completa, difícilmente disponible para el resto de los años que se incluyen en nuestro trabajo.

Sobre este particular, el cuadro 1 proporciona datos relevantes que merecen ser reseñados. En primer lugar, la preponderancia de la banca privada española que operaba bajo la forma jurídica de sociedad anónima, que ya gestionaba en el citado año el 80,7\% del pasivo de la banca en España. En segundo lugar, lo parejo que en los distintos sectores de negocio (bancos privados, casas de banca y banca extranjera) era el peso de las cuentas de pasivo clientes: en torno al 52\%. Tercero, la preponderancia de las cuentas corrientes, que significaban en su conjunto cerca de la mitad en la composición de este pasivo, sobre todo dentro de la banca extranjera. Cuarto, la mayor cuantía que ya en esta fecha representaba en todos los sectores de negocio los saldos en «caja de ahorros» en relación con los depósitos suscritos a plazos superiores a un mes vista. Finalmente, poco más del 91\% de los depósitos a un mes vista (caja de ahorros) fueron gestionados por los bancos privados españoles que operaban como sociedades anónimas. Es decir, la administración de este tipo de ahorro fue muy pequeño entre la banca extranjera que actuaba en España y casi marginal entre las casas de banca y banqueros particulares. El ahorro popular bancario, contabilizado a partir de la citada Ley de Ordenación Bancaria de 1921 como cuenta acreedora hasta el plazo de un

9. Esta denominación de «cuentas de ahorro a plazos menores de un mes» es como se contabilizaban operativamente los depósitos de ahorro captados por la banca privada en el segmento del mercado financiero minorista en la mayor parte de sus balances.

10. Saldo de los capitales confiados por el público (clientes) bajo la forma de depósitos en cuenta corriente y depósitos suscritos a distintos plazos. Esta cuenta estaba comprendida dentro de la denominada pasivo exigible, que fue definida específicamente por Real Decreto 13/06/1922, Gaceta de Madrid 16-06-1922, p. 980, que aprobaba el reglamento por el que se había de regir el funcionamiento del Consejo Superior Bancario, art. $10^{\circ}, 2^{\circ}$. También definía otras cuentas consideradas problemáticas como la de activo realizable. 
CUADRO 1 - La banca privada en España, 1931. Estructura del pasivo clientes por sectores (valores a fin de año en pesetas)

\begin{tabular}{|c|c|c|c|c|c|c|}
\hline & $\begin{array}{l}\text { Caja de } \\
\text { ahorros } \\
\text { (depósitos } \\
\text { < 1 mes) }\end{array}$ & $\begin{array}{l}\text { Cuentas } \\
\text { corrientes }\end{array}$ & $\begin{array}{l}\text { Depósitos } \\
\text { a plazo } \\
\text { (>1 mes) }\end{array}$ & $\begin{array}{l}\text { Cuentas } \\
\text { corrientes } \\
\text { moneda } \\
\text { extranjera }\end{array}$ & $\begin{array}{l}\text { Pasivo } \\
\text { clientes } \\
(P C)\end{array}$ & $\begin{array}{c}\text { Total } \\
\text { pasivo } \\
(\mathrm{PT})\end{array}$ \\
\hline $\begin{array}{l}\text { Bancos } \\
\text { privados } \\
\text { españoles S.A. }\end{array}$ & 1.408.798.261 & 2.526.972.548 & 961.686 .888 & 347.302 .144 & 5.244 .759 .841 & 9.720374 .460 \\
\hline $\begin{array}{l}\text { Casas } \\
\text { de banca }\end{array}$ & 48.453 .000 & 215.585 .000 & 153.540 .000 & 40.771 .000 & 458.349 .000 & 864.879 .000 \\
\hline $\begin{array}{l}\text { Banca } \\
\text { extranjera }\end{array}$ & 79.643 .839 & 401.860 .044 & 59.085 .222 & 58.254 .464 & 598.483 .569 & 1.449.147.759 \\
\hline \multirow{2}{*}{$\begin{array}{l}\text { Total banca } \\
\text { privada }\end{array}$} & 1.536 .895 .100 & 3.144 .417 .592 & 1.174 .312 .110 & 446.327 .608 & 6.301 .592 .410 & 12.034 .401 .219 \\
\hline & \multicolumn{5}{|c|}{ Estructura del pasivo clientes por sectores de banca privada (\%) } & $\mathrm{PC} / \mathrm{PT}$ \\
\hline $\begin{array}{l}\text { Bancos } \\
\text { privados } \\
\text { españoles S.A. }\end{array}$ & 26,86 & 48,18 & 6,62 & 18,34 & 100,00 & 53,96 \\
\hline $\begin{array}{l}\text { Casas } \\
\text { de banca }\end{array}$ & 10,57 & 47,04 & 8,90 & 33,50 & 100,00 & 53,00 \\
\hline $\begin{array}{l}\text { Banca } \\
\text { extranjera }\end{array}$ & 13,31 & 67,15 & 9,73 & 9,87 & 100,00 & 41,30 \\
\hline \multirow{2}{*}{$\begin{array}{l}\text { Total banca } \\
\text { privada }\end{array}$} & 24,39 & 49,90 & 18,64 & 7,08 & 100,00 & 52,36 \\
\hline & \multicolumn{6}{|c|}{ Peso en cada sector de banca privada (\%) } \\
\hline $\begin{array}{l}\text { Bancos } \\
\text { privados } \\
\text { españoles S.A. }\end{array}$ & 91,67 & 80,36 & 77,81 & 81,89 & 83,23 & 80,77 \\
\hline $\begin{array}{l}\text { Casas } \\
\text { de banca }\end{array}$ & 3,15 & 6,86 & 9,13 & 13,07 & 7,27 & 7,19 \\
\hline $\begin{array}{l}\text { Banca } \\
\text { extranjera }\end{array}$ & 5,18 & 12,78 & 13,05 & 5,03 & 9,50 & 12,04 \\
\hline $\begin{array}{l}\text { Total banca } \\
\text { privada }\end{array}$ & 100,00 & 100,00 & 100,00 & 100,00 & 100,00 & 100,00 \\
\hline
\end{tabular}

Fuente: Anuario Económico Financiero editado por El Financiero, 1931.

mes, constituyó un ámbito de negocio que concernió e interesó fundamentalmente a un número importante de los bancos privados españoles que estaban implicados en un proceso de expansión, tanto territorial como de tipos de inversiones, durante esos años. ${ }^{11}$

11. Roldán y García Delgado (1973), Muñoz (1978) y Belford (1979). 
CUADRO 2 - La banca privada española (S.A.), 1931. Estructura del pasivo clientes según mercados de actuación (valores a fin de año en pesetas)

\begin{tabular}{|c|c|c|c|c|c|c|}
\hline & $\begin{array}{l}\text { Caja de } \\
\text { ahorros } \\
\text { (depósitos } \\
<1 \text { mes) }\end{array}$ & $\begin{array}{l}\text { Cuentas } \\
\text { corrientes }\end{array}$ & $\begin{array}{c}\text { Depósitos } \\
\text { a plazo } \\
\text { (>1 mes) }\end{array}$ & $\begin{array}{l}\text { Cuentas } \\
\text { corrientes } \\
\text { moneda } \\
\text { extranjera }\end{array}$ & $\begin{array}{l}\text { Pasivo } \\
\text { clientes } \\
\text { (PC) }\end{array}$ & $\begin{array}{c}\text { Total } \\
\text { pasivo } \\
\text { (PT) }\end{array}$ \\
\hline $\begin{array}{l}\text { Nacional } \\
\text { (5 bancos) }\end{array}$ & 753.374 .762 & 1.509 .977 .855 & 401.478 .393 & 237.526 .017 & 2.902.357.027 & 5.223 .619 .252 \\
\hline $\begin{array}{l}\text { Regional } \\
\text { (32 bancos) }\end{array}$ & 575.921 .674 & 677.453 .873 & 427.817 .950 & 87.255 .970 & 1.768 .449 .467 & 3.086 .669 .458 \\
\hline $\begin{array}{l}\text { Local } \\
\text { (54 bancos) }\end{array}$ & 79.501 .825 & 339.540 .820 & 132.390 .545 & 22.520 .157 & 573.953.347 & 1.410 .085 .750 \\
\hline \multirow[t]{2}{*}{ Total bancos } & 1.408.798.261 & 2.526.972.548 & 961.686 .888 & 347.302 .144 & 5.244 .759 .841 & 9.720 .374 .460 \\
\hline & \multicolumn{5}{|c|}{ Estructura del pasivo clientes según mercados de actuación (\%) } & $\mathrm{PC} / \mathrm{PT}$ \\
\hline Nacional & 25,96 & 52,03 & 13,83 & 8,18 & 100,00 & 55,56 \\
\hline Regional & 32,57 & 38,31 & 24,19 & 4,93 & 100,00 & 57,29 \\
\hline Local & 13,85 & 59,16 & 23,07 & 3,92 & 100,00 & 40,70 \\
\hline \multirow[t]{2}{*}{ Total bancos } & 26,86 & 48,18 & 18,34 & 6,62 & 100,00 & 53,96 \\
\hline & \multicolumn{6}{|c|}{ Peso de cada cuenta de pasivo clientes según mercados de actuación (\%) } \\
\hline Nacional & 53,48 & 59,75 & 41,75 & 68,39 & 55,34 & 53,74 \\
\hline Regional & 40,88 & 26,81 & 44,49 & 25,12 & 33,72 & 31,75 \\
\hline Local & 5,64 & 13,44 & 13,77 & 6,48 & 10,94 & 14,51 \\
\hline Total bancos & 100,00 & 100,00 & 100,00 & 100,00 & 100,00 & 100,00 \\
\hline
\end{tabular}

Fuente: Anuario Económico Financiero editado por El Financiero, 1931.

Centrando ahora la atención en este tipo de bancos, podemos decir que aquellos de ámbito nacional — no más de cinco bancos - ${ }^{12}$ administraban cerca del 54\% del pasivo utilizable. El 31,7\% lo gestionó la banca regional —32 bancos $-{ }^{13} \mathrm{y}$ el resto quedó en manos de la banca local -54 bancos-.${ }^{14} \mathrm{De}$ la totalidad de los recursos disponibles, aquellos confiados bajo la forma de depósitos a la vista y a distintos plazos (pasivo clientes) importaban ya poco más de la mitad. Y dentro de la estructura de este modelo de pasivo, las cuen-

12. Mediante la creación de una importante red de sucursales y agencias en los principales núcleos urbanos del país, a partir del final de la Primera Guerra Mundial, la gran Banca de Madrid y Bilbao «se hace nacional». En 1926, los bancos Hispano Americano, Español de Crédito, Central, Bilbao y Vizcaya acumulaban ya el 51,7\% de las sucursales entonces abiertas. Vid. Muñoz (1978). También Pueyo Sánchez (2006).

13. Entendemos por banca regional aquellos establecimientos cuya política de expansión por medio de sucursales se circunscribió preferentemente a la región en que se localizaba la razón social, extendiendo también su influencia a las provincias limítrofes.

14. Los bancos locales eran aquellos cuya zona fundamental de operaciones e influencia se ajustaba prioritariamente a la ciudad en la que se ubicaba la sede social. 
tas corrientes pesaban por encima del $50 \%$ en el conjunto de los bancos de ámbito nacional, como también en aquellos otros cuyo mercado de actuación era local. El peso de este tipo de saldo fue menor entre los bancos regionales, y comparativamente mayor el interés por la captación de depósitos a distintos plazos, sobre todo aquellos hasta un mes vista. De la lectura combinada de los datos representados en los cuadros anteriores puede concluirse que el ahorro popular bancario, contabilizado dentro de este último patrón de depósito, fue, como se ha dicho antes, un espacio de negocio que concernió e interesó a un número relevante de los bancos privados españoles, y que dentro de estos tuvo mayor significación entre aquellos establecimientos cuyo mercado de actuación fue de alcance regional.

La nueva serie «caja de ahorros» de bancos que presentamos atiende a lo gestionado por estas empresas privadas que operaron como sociedades anónimas. Para su confección hemos partido de los datos que bajo las distintas rúbricas ya mencionadas - y que indistintamente fueron usadas para contabilizar los saldos de ahorro popular hasta la aprobación de un único modelo de balance a que obligó la Ley de Ordenación Bancaria de 29 de diciembre de 1921 - ${ }^{15}$ figuraban en el pasivo, dentro del balance general que cada banco dio a conocer a sus accionistas en la presentación de sus memorias anuales. ${ }^{16}$ El resultado obtenido, y su comparación con las estimaciones hasta ahora conocidas, aparece reflejado en el cuadro 3.

Como puede observarse, la nueva serie construida proyecta un camino que discurre todo el tiempo entre medias de la que proporciona, por el lado superior, el Anuario Financiero y de Sociedades Anónimas de España, y, por el lado inferior, el resto de los anuarios consultados. En el primer caso, la diferencia es debida, fundamentalmente, a que el citado anuario, dentro de la signatura «caja de ahorros», contabilizaba también los depósitos a plazo superiores a un mes vista. En el resto, las razones que lo explican son varias, y a veces se combinaban. El Anuario Financiero de Bilbao, por ejemplo, algunos años $(1909,1926,1927)$ también sumaba el ahorro suscrito a distintos plazos.

15. En relación con la banca privada, esta ley establecía en el Ministerio de Hacienda una Comisión de Ordenación de la Banca Privada, constituida por un comisario regio nombrado por el Gobierno por acuerdo del Consejo de Ministros, a propuesta del de Hacienda, y un Consejo Superior Bancario, presidido por el citado comisario. Entre sus cometidos, este consejo debía formar la estadística bancaria española y extranjera establecida en España, con todos los elementos que permitieran conocer cuál era la situación financiera bancaria con una periodicidad trimestral. Y además debía proponer al Gobierno la forma en que debían establecerse y publicarse los balances de todos los bancos y banqueros españoles y extranjeros establecidos en España. Por Real Orden de 21 de septiembre de 1922 se aprobó con carácter provisional el modelo de balance propuesto (Gaceta de Madrid, 23 de septiembre de 1922, pp. 266). Este quedó definitivamente aprobado por Real Orden de 8 de abril de 1924 (Gaceta de Madrid, 9 de abril de 1924, pp. 199-200). Un análisis muy crítico del modelo propuesto en De Roca (1922), pp. 1-7.

16. Hemos consultado y utilizado todos los balances de todos los bancos que operaron como sociedades anónimas entre 1900 y 1935. 
CUADRO 3 - La banca privada española, 1900-1935. Evolución de la cuenta «caja de ahorros»

\begin{tabular}{|c|c|c|c|c|c|}
\hline & \multirow{2}{*}{ Nueva serie } & \multirow{2}{*}{ Serie INE } & \multicolumn{3}{|c|}{ Serie anuario(s) financiero(s) } \\
\hline & & & Vizcaya & Bilbao & España \\
\hline 1900 & 75.974 .511 & 48.000 .000 & & & 100.842 .215 \\
\hline 1901 & 77.391 .982 & 50.000 .000 & & & 101.855 .080 \\
\hline 1902 & 98.175 .375 & 52.000 .000 & & & 121.456 .188 \\
\hline 1903 & 121.160 .452 & 55.000 .000 & & & 147.146 .311 \\
\hline 1904 & 134.393 .745 & 84.333 .000 & 84.333 .000 & 84.333 .000 & 163.787 .703 \\
\hline 1905 & 150.380 .578 & 91.599 .000 & 91.599 .000 & 91.599 .000 & 182.179 .236 \\
\hline 1906 & 163.773 .893 & 95.924 .000 & 95.224 .000 & 95.224 .000 & 197.063 .183 \\
\hline 1907 & 169.853 .171 & 100.602 .000 & 100.602 .000 & 100.602 .000 & 208.348 .709 \\
\hline 1908 & 179.321 .855 & 141.607 .000 & 141.627 .000 & 141.627 .000 & 218.692 .346 \\
\hline 1909 & 188.729 .402 & 149.915 .000 & 249.915 .000 & 249.915 .000 & 231.117 .278 \\
\hline 1910 & 203.423 .305 & 158.827 .000 & 158.827 .000 & 158.827 .000 & 243.556 .607 \\
\hline 1911 & 218.607 .502 & 164.768 .000 & 164.768 .000 & 164.768 .000 & 259.186 .772 \\
\hline 1912 & 230.692 .407 & 168.509 .000 & 168.508 .000 & 168.508 .000 & 271.762 .605 \\
\hline 1913 & 242.688 .788 & 156.124 .000 & 156.123 .000 & 156.123 .000 & 284.372.334 \\
\hline 1914 & 201.681 .418 & 136.734 .000 & 136.734 .000 & 136.734 .000 & 243.051 .567 \\
\hline 1915 & 212.103 .439 & 146.803 .000 & 146.802 .000 & 146.802 .000 & 303.032 .339 \\
\hline 1916 & 239.299 .259 & 158.674 .000 & 158.673 .000 & 158.673 .000 & 327.561 .356 \\
\hline 1917 & 227.068 .975 & 159.761 .000 & 159.761 .000 & 159.761 .000 & 337.566 .681 \\
\hline 1918 & 316.392 .730 & 172.315 .000 & 172.315 .000 & 172.315 .000 & 414.926 .416 \\
\hline 1919 & 382.240 .865 & 183.203 .000 & 183.203 .000 & 183.203 .000 & 537.112 .109 \\
\hline 1920 & 472.102 .745 & 186.596 .000 & 186.596 .000 & 186.596 .000 & 692.239 .953 \\
\hline 1921 & 489.839.734 & 202.742 .000 & 415.006 .608 & 415.006 .608 & 731.558 .798 \\
\hline 1922 & 517.985 .142 & 435.539 .000 & 493.718 .135 & 493.718 .135 & 977.215 .385 \\
\hline 1923 & 548.941 .349 & 487.290 .000 & 487.290 .078 & 486.829 .472 & 1.125 .913 .063 \\
\hline 1924 & 615.619 .293 & 505.900 .000 & 513.147 .777 & 513.147 .777 & 1.125 .596 .938 \\
\hline 1925 & 620.977 .498 & 504.636 .000 & 483.395 .086 & 483.395 .086 & 1.109 .522 .857 \\
\hline 1926 & 679.377 .640 & 438.819 .000 & 1.093 .920 .470 & 1.093 .920 .470 & 1.212 .556 .403 \\
\hline 1927 & 796.376 .411 & 688.315 .000 & 1.358 .816 .494 & 1.358 .016 .494 & 1.413 .343 .032 \\
\hline 1928 & 941.020 .992 & 702.744 .000 & 1.706 .862 .181 & 724.800 .095 & 1.699 .520 .331 \\
\hline 1929 & 1.211 .556 .513 & 1.065 .513 .000 & 1.983 .154 .578 & 978.745 .743 & 2.047 .930 .453 \\
\hline 1930 & 1.377 .302 .411 & 1.265 .907 .000 & 2.503 .969 .580 & 1.359 .007 .162 & 2.252.112.448 \\
\hline 1931 & 1.408.798.261 & 1.279 .545 .000 & 2.324.379.812 & 1.366 .643 .756 & 2.085.163.627 \\
\hline 1932 & 1.640 .296 .213 & 1.020 .164 .000 & 2.551.326.307 & 1.563.963.026 & 2.226 .796 .486 \\
\hline 1933 & 1.780 .723 .128 & 1.094 .513 .000 & 2.725.958.232 & 1.742 .617 .069 & 2.414 .261 .129 \\
\hline 1934 & 1.988 .700 .859 & 1.091 .300 .000 & 2.983 .105 .465 & 1.882 .029 .541 & 3.008 .989 .499 \\
\hline 1935 & 2.219 .218 .445 & 1.090 .600 .000 & 3.396 .283 .653 & 2.199.813.708 & 3.396 .283 .653 \\
\hline
\end{tabular}

Fuentes: Anuario Financiero y de Valores Mobiliarios (1916-1917); Anuario Financiero y de Sociedades Anónimas de España (1918-1940); Anuario Financiero de Bilbao (1917-1936); Anuario Económico Financiero editado por El Financiero (1932-1934); Anuario Financiero del Banco de Vizcaya (1917-1941); Anuario Estadístico de España (1912-1936); «Balances bancarios», en Boletín del Consejo Superior Bancario (1923-1936); «Balance(s) general(es)», [en] Memoria(s) presentada a la Junta General de Accionistas.

Y lo mismo hizo el Anuario Financiero del Banco de Vizcaya a partir de 1926. Aunque, por lo general, lo más frecuente fue la carencia de datos de algunos bancos; y en ausencia de ello, el uso de cifras de años anteriores. El Anuario 
GRÁFICO 2 - Banca privada española, 1900-1935. Evolución del saldo de «caja de ahorros». Serie nueva (en millones de pesetas)

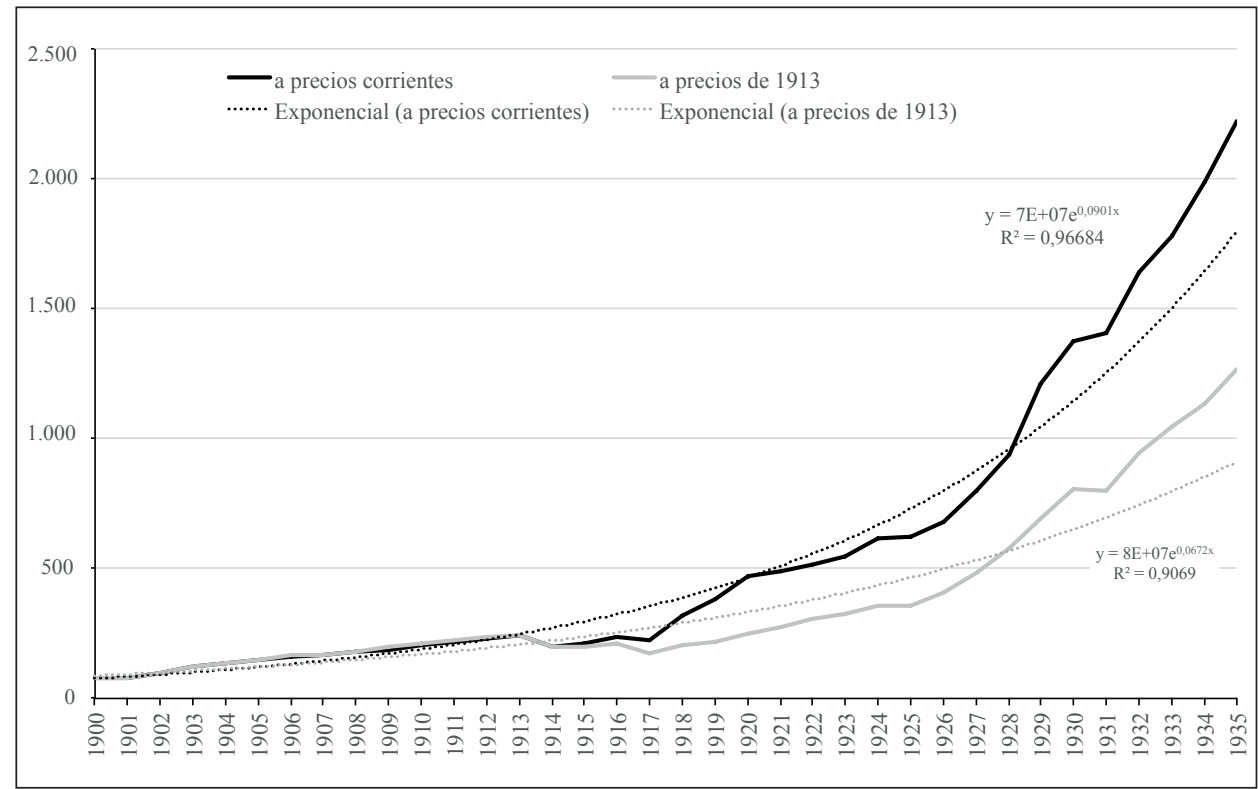

Fuente: «Balance(s) general(es)», [en] Memoria(s) [1900-1935], y «Balances bancarios», en Boletín del Consejo Superior Bancario (1923-1936).

Estadístico de España solo contabilizaba los grandes bancos nacionales y regionales; y entre estos últimos, no siempre todos.

A lo largo de todo el período aquí considerado, la captación del ahorro popular por parte de los bancos reflejó una progresión exponencial. La tasa de variación media acumulativa entre 1900-1935 fue del 11,9\% a precios corrientes y del 9,7\% a precios constantes, es decir, poco más de 6 y 7 puntos porcentuales por encima del incremento que marcaron respectivamente tanto el PIB a precios de mercado como el PIB por habitante; un ascenso, por tanto, relevante, que logró superar el efecto inflacionista. Este progreso fue especialmente acentuado durante el primer y tercer decenio, con tasas de dos dígitos, y más particularmente en los quinquenios 1900-1904 y 1925-1929.

Estos decenios acotan, respectivamente, las dos fases alcistas que caracterizan la evolución cíclica de este modelo de depósito bancario. La primera tuvo su apoyo en el gran auge finisecular. El final del conflicto colonial dio paso a una enorme afluencia de capitales a la búsqueda de un rápido acomodo, que en el campo de la intermediación financiera se sustanció en una relevante expansión bancaria, con la fundación de entidades que pronto observaron oportunidades de negocio más allá de la localidad en la que asentaban 
su sede social, y en una población trabajadora que en medio de esta bonanza empezaba a disfrutar de una mayor capacidad de ahorro. Así, durante los cinco primeros años del nuevo siglo, el saldo de la caja de ahorros de los bancos respecto del PIB pasó de un $0,74 \%$ a un $1,14 \%$. Pero con todo, para la capacidad de captación de este ahorro popular, fue un período de bonanza corto, que se suavizó a partir de 1904, y mucho más al compás del exiguo crecimiento de una economía española ya por entonces muy afectada por el negativo impacto que ocasionaba el desequilibrio que en las finanzas del Estado empezaban a causar los crecientes gastos de la guerra de Marruecos. Finalmente, el pánico que siguió a las primeras noticias aparecidas en los diarios nacionales anunciando el comienzo de la Primera Guerra Mundial terminó por cambiar el signo positivo en la capacidad de captación de este tipo de ahorro. A fines de 1914, el saldo existente cayó respecto del año inmediatamente anterior nada menos que un $17,7 \%$. Y hubieron de pasar siete años para recuperar la cifra inmediatamente previa al inicio del conflicto internacional. La acusada pérdida de capacidad adquisitiva de los salarios explica bastante las dificultades que encontró la banca para aumentar las magnitudes de esta cuenta a lo largo de todo el período bélico, pues hasta 1921 no se logró alcanzar la misma proporción respecto del PIB que ya se había conseguido en 1912: el $1,80 \%$.

GRÁFICO 3 - Banca privada española, 1900-1935. Saldo «caja de ahorros»/PIB (\%)

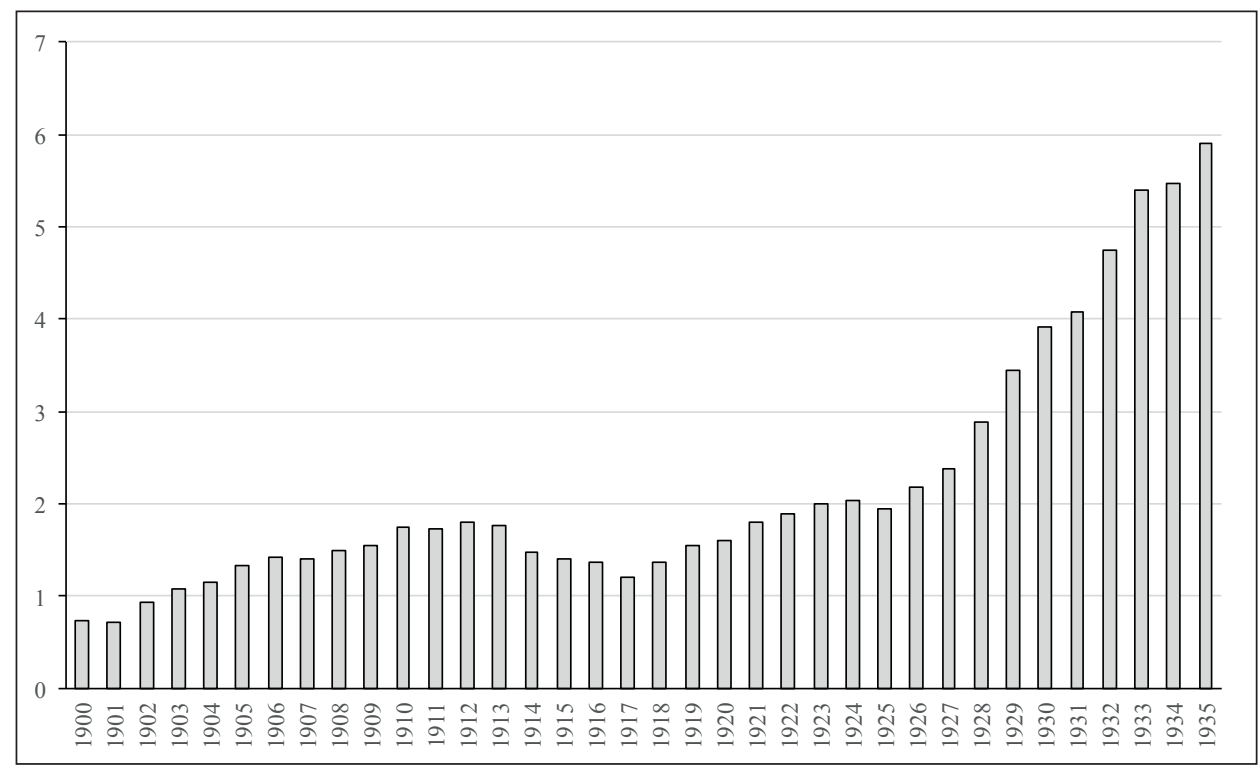

Fuente: Datos del PIB, en Prados de la Escosura (2003: Cuadro A.2.7), pp. 286-289. Datos de saldos de cajas de ahorros bancarias: véase cuadro 3 , «Nueva serie». 
Desde los años iniciales del mencionado conflicto, pero sobre todo a partir de la finalización de este, la cada vez más extendida práctica de monetización indirecta de la deuda fue aprovechada por una banca privada que, si exceptuamos los llamativos casos de quiebra que acontecieron en mayor número en Cataluña, mostró una clara determinación a invertir sus recursos en un doble y paralelo proceso de concentración por medio de la absorción de entidades menores y de expansión a través de la apertura de sucursales. Esta renovada estructura bancaria fue ampliando el campo de sus operaciones hacia el ámbito de la promoción industrial. Tal orientación, que en un principio venía estimulada por los beneficios extraordinarios que se derivaban del hecho mismo de la neutralidad en el conflicto mundial, se asentó con más fuerza tras la promulgación de la Ley de Ordenación Bancaria de 1921, que introducía nuevas reglas mucho más claras como, también, más modernas en la organización y gestión de los asuntos financieros. Fue esta renovación en las funciones que desempeñar por la banca mixta y su capacidad a la hora de suministrar liquidez a casi todos los sectores del mercado nacional, lo que proporcionó el germen de solidez del nuevo ciclo expansivo de la economía que se inició en 1923.

Los años de la dictadura de Primo de Rivera acotan, así, una etapa de renovadas expectativas al ahorro privado nacional, favorecidas también por un ambiente más sosegado, al que contribuyó la finalización de la guerra de Marruecos, la estabilidad política, el control social, la mayor integración de los mercados financieros y la reducción del déficit comercial y de la deuda flotante. Entre 1923 y 1929, por tanto, la economía española creció a una tasa media anual del $4,19 \%$, sustentada en una elevada proporción en el impulso que procedía de un sector industrial muy protegido de la competencia exterior, estimulado por los planes de obras públicas, y eficazmente socorrido en la demanda adicional de dinero por una banca privada que encontró mayor apoyo en el Banco de España y en el mecanismo de pignoración automática de la deuda pública. En un entorno aún de lento crecimiento de una población activa todavía mayoritariamente vinculada al sector primario, se apreciaba ya un sensible cambio en la estructura ocupacional en favor del sector minero e industrial. Junto a ello, los salarios reales se fueron recuperando en 1928 se habían multiplicado por 1,5 respecto de 1913-. En este contexto, cada vez más bancos abrieron cajas de ahorro en la medida en que se expandían inaugurando sucursales. Ello tuvo su reflejo en la apreciable proporción que en relación con el PIB fue adquiriendo este tipo de depósito bancario: si en 1923 este representaba el $2 \%$ del PIB, superada la crítica coyuntura que atravesó la banca vasco-navarra - una zona del país en la que la cultura de ahorro popular estaba muy extendida-, en 1929 ya significaba el 3,4\%. Salvado también el adverso escenario económico y social que acompañó los primeros meses de andadura de la Segunda República — retirada de más del 10\% 
de los depósitos bancarios totales en el trimestre comprendido entre el 1 de abril y el 30 de junio, cierre de la Bolsa de Madrid durante ocho días-, que minó la confianza de los ahorradores, sobre todo de aquellos con mayor capacidad, en 1935 la proporción del saldo total de caja de ahorros que ya gestionaron los bancos suponía el 5,9 del valor del PIB de ese mismo año. ${ }^{17} \mathrm{En}$ definitiva, a lo largo de los primeros 36 años del siglo Xx, la cuenta «caja de ahorros» de los bancos fue adquiriendo un protagonismo creciente dentro del pasivo, merecedor, por tanto, de un estudio más detallado. A este propósito destinamos el siguiente apartado.

\section{La relación entre el ahorro popular y la banca privada}

En 1874, año en que se concedió al Banco de España el privilegio de emisión, el saldo en la caja de ahorros de los bancos representaba un exiguo $1 \%$ respecto del pasivo total que gestionaron, un 1,8\% del pasivo clientes que todo el sistema de banca privada logró captar y un 2,7\% del dato que en el mismo año consiguieron las cuentas corrientes. En 1900, las proporciones, sin embargo, ya habían cambiado muy sustancialmente: ascendieron a un $14,2 \%$ con relación al total de pasivo, a un $25,2 \%$ dentro del pasivo clientes y a un $41,2 \%$ de la cifra alcanzada por las cuentas corrientes.

Estas magnitudes fueron claro reflejo de lo que aconteció en los últimos años del siglo XIX. Hay que decir, así, que la crisis económica que acompañó las guerras coloniales que se desataron en 1895 fue breve y poco intensa, pero la expansión de la inmediata posguerra fue rapidísima y de enorme magnitud, como también reveló la contabilidad financiera de los bancos. Entre 1896 y 1901, el PIB al coste de los factores de la economía española creció un $28 \%$, es decir, a una tasa media interanual del 5,1\%. ${ }^{18}$ Ahora bien, no debe olvidarse que la producción industrial per cápita española apenas constituía en este período intersecular una quinta parte de la británica, lo que expresa el «atraso relativo» que esta economía del sur europeo aún padecía, y que todavía se manifestaba en una industria tradicional y regionalmente muy concentrada, amén de escasamente competitiva. Pero también, en estos años, tuvo lugar una cierta modernización tecnológica y organizativa en sectores tales como el siderúrgico, la industria de construcciones mecánicas y metálicas, la química o la industria eléctrica. Este impulso renovador surgió al calor de lo que se ha dado en llamar vía nacionalista del capitalismo español

17. Los datos de PIB y PIB por habitante, en Prados de la Escosura (2003). El índice de precios al consumo, en Maluquer de Motes (2013). La información sobre población activa, en Nicolau (2005). Datos de salarios reales, en Maluquer de Motes y Llonch (2005), Roldán y García Delgado (1973, vol. 1), pp. 187-199.

18. Gómez Mendoza (1997), Carreras (1999). 
que, animado por un ambiente internacional igualmente favorable y contagioso, inauguró el «arancel de guerra» de Cánovas (1891) y ahondó el «arancel Salvador» de 1907 y la ley de industrias que Antonio Maura promovió al año siguiente. ${ }^{19}$

En medio de este clima generalizado de creciente nacionalismo económico, el tránsito al siglo Xx constituye una etapa que los historiadores han bautizado ya como gran auge finisecular; un período en el que la alteración, tanto cuantitativa como cualitativamente, de las relaciones entre ahorro e inversión posibilitó una auténtica «fiebre» de creación de empresas, así como un incremento de la producción, que afectaron tanto a las cifras propiamente del sector secundario como a las de los servicios. Dentro del primero, se beneficiaron especialmente de este espectacular auge promocional la industria agroalimentaria, la química, eléctrica, siderometalúrgica, papel y artes gráficas, y en el sector servicios fueron el transporte, el comercio y la banca quienes más acusaron el movimiento masivo de fundación de sociedades. Espectacular fue el despegue de la banca privada, que atrajo una gran cantidad de recursos no solo a las entidades hasta entonces existentes, sino sobre todo a los nuevos establecimientos que en esos años interseculares se fundaron.

La siguiente relación de gráficos refleja la evolución de los saldos y de la estructura del pasivo clientes para todo el sector de banca privada doméstica que operaba como sociedad anónima. De su lectura combinada se pueden concretar varias pautas de interés. En primer lugar, el peso que siempre tuvieron las cuentas corrientes en relación con el resto de las partidas contables que estructuran el pasivo clientes, sobre todo entre la banca de ámbito nacional. En segundo lugar, la progresión exponencial del remanente en caja de ahorros, principalmente en aquellos bancos cuya zona fundamental de influencia era de ámbito regional. Dentro de esta cuenta, los años de la Primera Guerra Mundial pasaron mayor factura en los de ámbito nacional y, sobre todo, en los bancos locales. Entre estos últimos, además, las crisis que sobrevinieron en determinadas plazas comerciales - Barcelona en 1921 o Bilbao en 1925 - dejaron su particular y profunda huella negativa. En tercer lugar, es de señalar que la intensa progresión que el ahorro popular registró a lo largo de la década de 1930 hizo aproximar sus saldos a los de las cuentas corrientes, e incluso a igualarse las cifras en el caso de los bancos regionales. Finalmente, hasta la década de 1920, los depósitos a plazo fijo no superaron en ningún momento a los de la caja de ahorros; si bien, a partir de esos años, la evolución de una y otra cuenta fue mucho más pareja, sobre todo en los bancos regionales, aunque lo llamativo también fue el mayor peso que entre los bancos de ámbito local fue adquiriendo el plazo fijo.

19. Sabaté Sort (1996). 

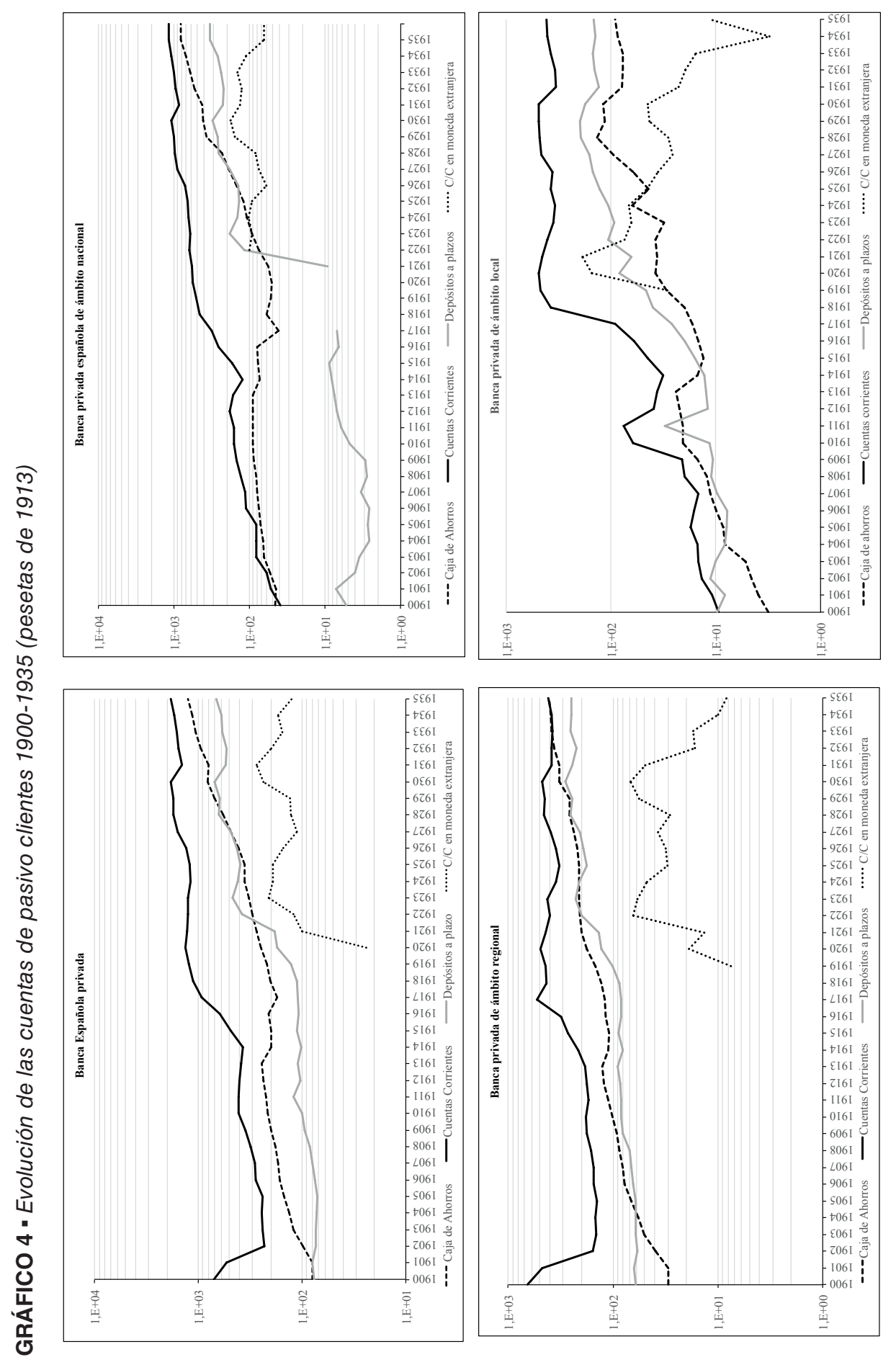

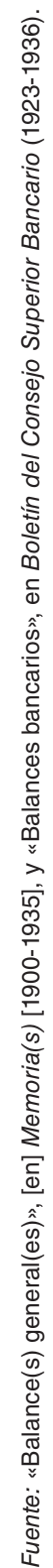




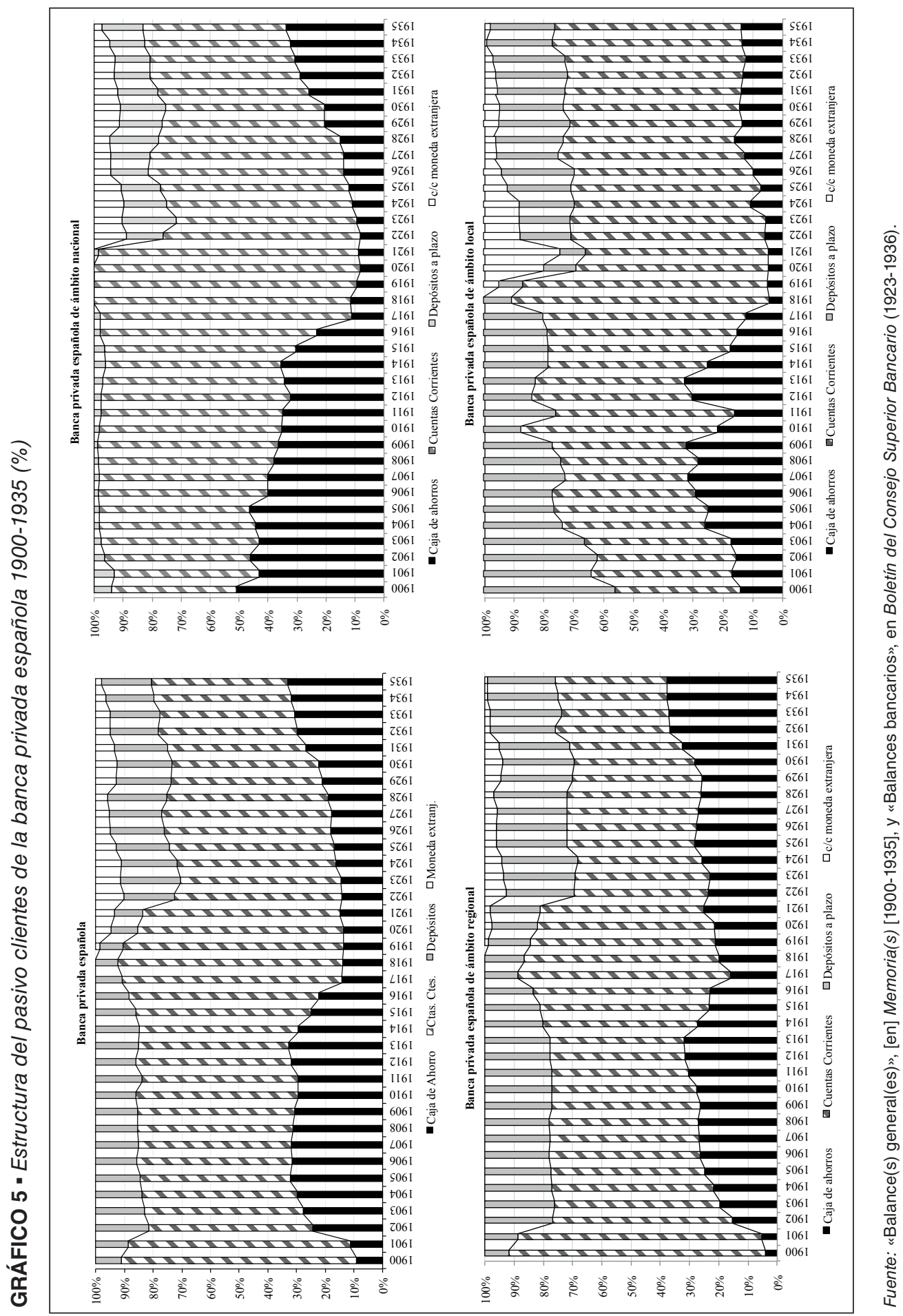


Como reiteradamente hemos apuntado, a lo largo del primer tercio del siglo $\mathrm{XX}$, los remanentes en caja de ahorros fueron adquiriendo un protagonismo creciente dentro del pasivo ajeno de los bancos, y muy señaladamente a lo largo del primer y tercer decenio. El primero se sustentó en la mayor capacidad de ahorro que facilitó el gran auge finisecular; el segundo, en las renovadas expectativas que al ahorro privado nacional dio ocasión el nuevo ciclo expansivo de la economía a partir de 1923. El ahorro popular bancario representó una cuota de negocio que concernió e interesó sobre todo a un relevante número de los bancos privados españoles que operaron como sociedades anónimas; y entre estos, con especial y creciente interés, entre aquellos establecimientos cuya zona de influencia fue preferentemente de alcance regional. Este tipo de sociedades, que a comienzos de siglo captaban en torno al $37 \%$ del saldo total que gestionó por entonces el conjunto de la banca privada, poco a poco fue aumentando la cuota en detrimento de la banca de ámbito nacional. Los grandes bancos españoles de la época pasaron, así, de atraer más de la mitad de estos depósitos en los primeros años, a caer por debajo del $30 \%$ a finales de la Primera Guerra Mundial, y a poco más del 20\% en los comienzos de la década de 1920. En estos mismos años, la banca regional ya acumulaba más del $70 \%$, mientras que la banca local no llegaba, al igual que durante todo el primer tercio de ese siglo, al 10\%. Pero también es de resaltar como a partir del señalado nuevo ciclo expansivo, la gran banca volvió a recuperar el protagonismo perdido. En 1923 gestionaba el 30,6\% del total del saldo en caja de ahorros de la banca española, frente al $65,3 \%$ que acumulaban los bancos regionales. Seis años después, en 1929, estas proporciones ya se habían alterado sustancialmente: $56 \%$ frente a 37,5\%; y todavía mucho más en vísperas de iniciarse la Guerra Civil de 1936: 63,8\% frente al 32,0\% que representaba la banca regional.

Detrás de esta recuperación de los bancos de mayor dimensión estuvo el éxito de incidir en la expansión por medio de la apertura de una importante red de sucursales y agencias en los principales núcleos urbanos del país. Por un lado, esta práctica permitió entrar en competencia con los bancos regionales en sus particulares áreas de influencia; por otro lado, facilitaba drenar recursos en zonas del país en las que las prácticas más habituales de intermediación aún seguían en manos de casas de banca y banqueros particulares.

Los datos reconstruidos permiten, finalmente, atender otro aspecto más que complementa todo lo anterior, como es la distribución regional de este tipo de ahorro y cómo esta misma partición fue variando a lo largo del período aquí considerado. Tales cambios, además, nos alumbran de particulares coyunturas económicas, de amplitud e intensidad diferentes entre sí, que terminaban afectando a la confianza del ahorrador y, por tanto, a la capacidad de captación del excedente de renta no consumida.

La Ley de Ordenación Bancaria de 1921 dividía el país en las mismas tres zonas bancarias que hemos utilizado para la confección del gráfico 7. A la luz 
GRÁFICO 6 - Banca privada española, 1900-1935. Distribución de la cuenta «caja de ahorros» según mercados de actuación (\%)

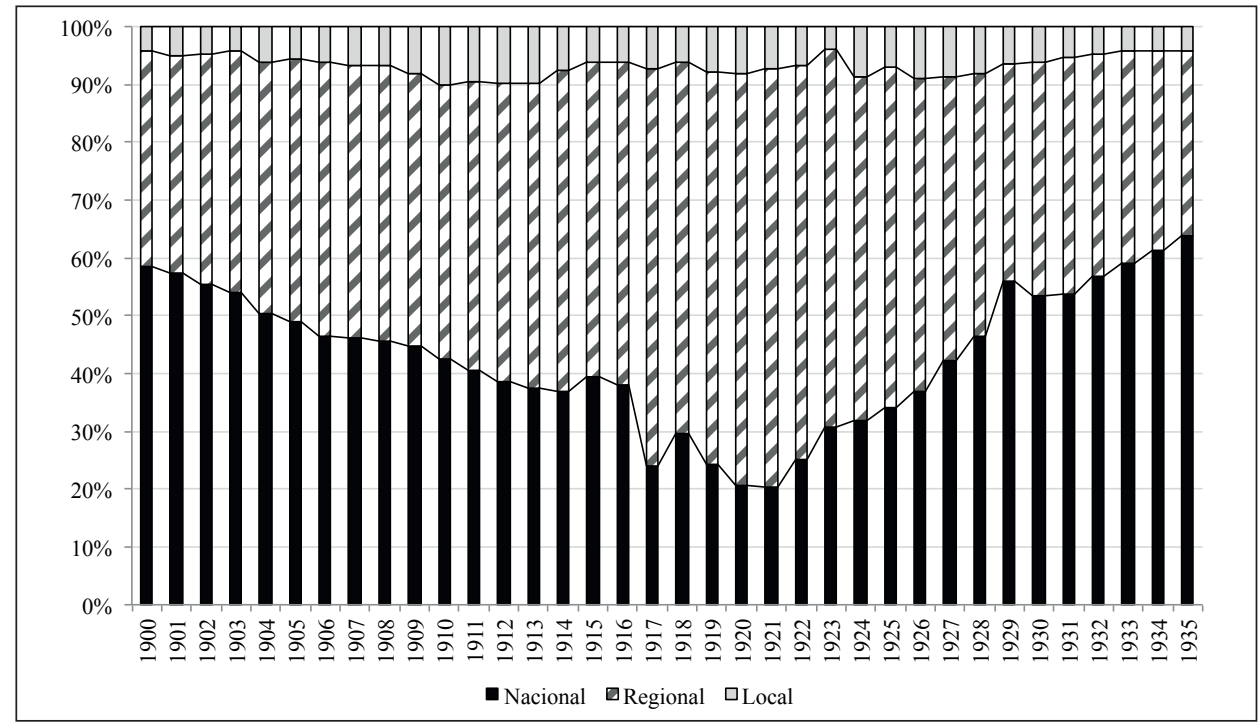

Fuente: «Balance(s) general(es)», [en] Memoria(s) [1900-1935], y «Balances bancarios», en Boletín del Consejo Superior Bancario (1923-1936).

GRÁFICO 7 - Banca privada española, 1900-1935. Distribución de la cuenta «caja de ahorros» según zonas bancarias (\%)

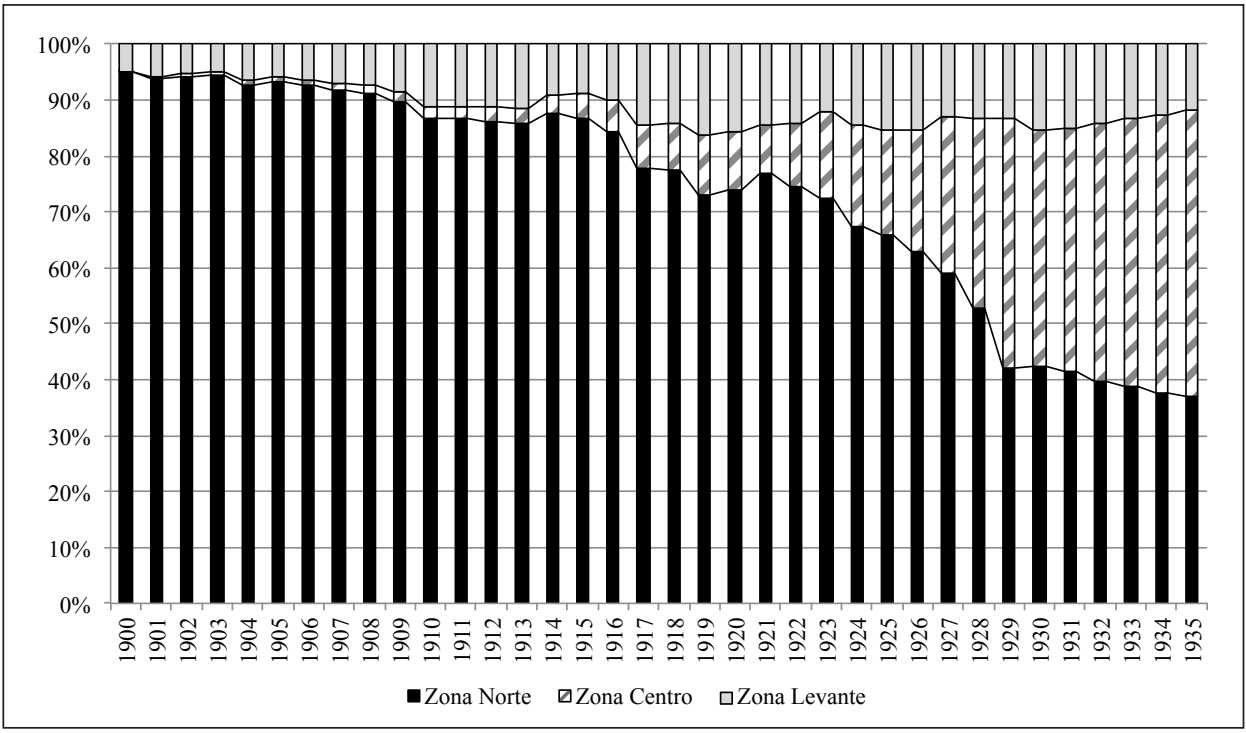

Fuente: «Balance(s) general(es)», [en] Memoria(s) [1900-1935], y «Balances bancarios», en Boletín del Consejo Superior Bancario (1923-1936). 
de la imagen que en este se proyecta, combinada su lectura con los datos que aportamos en el cuadro 4, se pueden resaltar las siguientes observaciones. En primer lugar, el mayor atractivo que hasta finalizada la Primera Guerra Mundial mostraron las regiones del norte como principales receptoras y gestoras del ahorro popular. Durante el primer decenio, esta zona del país acumuló un saldo por encima del 90\%. De este porcentaje fueron mayoritariamente responsables aquellos bancos que tenían domiciliada su sede social en el País Vasco, y particularmente en la plaza comercial de Bilbao — solamente este enclave acumuló de media en este mismo primer decenio un remanente que suponía más del $80 \%$ de lo contabilizado en el conjunto del país-. Con el inicio del nuevo siglo, la cultura del ahorro entre los grupos sociales más modestos estaba ya muy extendida en esta parte industriosa del país; una propensión a ahorrar que contribuyó a cultivar aún más los nuevos establecimientos que se fueron creando y que, entrando en competencia con el Banco de Bilbao, abrieron inmediatamente cajas de ahorro: Banco del Comercio (1891), Banco de Vizcaya (1901) y Crédito de la Unión Minera (1901); en Guipúzcoa: Banco Guipuzcoano (1899), Banco de San Sebastián (1909) y Banco de Tolosa (1911); en Álava: Banco de Vitoria (1900). Es más, tanto el Banco de Bilbao como, con más empuje, el Banco de Vizcaya muy pronto comenzaron a entretejer una compacta red de sucursales y agencias que desde las respectivas sedes sociales radicadas en Bilbao fueron extendiendo sus tentáculos a los núcleos urbanos próximos, primero de la propia provincia, seguidamente de las provincias limítrofes, y poco a poco hacia las principales capitales del país, empezando por Madrid y Barcelona. Todo este empeño tuvo sus resultados: entre 1900 y 1935, el saldo de caja de ahorros del conjunto de los bancos radicados en el País Vasco creció, descontada la influencia de los precios, a una tasa interanual del $4 \%$.

Dentro de esta misma Zona Norte, también fue relevante la capacidad de captación de este tipo de ahorro de los bancos fundados en la ciudad de Santander, que en los primeros años de la década de 1920 llegaron a representar una cuarta parte del remanente total acumulado en el conjunto del país. Y también de la banca asturiana, muy beneficiada por la pujanza de su economía en estos años que consideramos.

La segunda observación que destacar tiene que ver con el fuerte empuje que a partir del fin de la Primera Guerra Mundial caracterizó a la banca radicada en Madrid, cuyos más importantes bancos también terminaron abriendo una caja de ahorros. Los bancos Hispano Americano y Central lo hicieron en 1922, y un año después anunciaba lo propio el Español de Crédito. ${ }^{20}$ A comienzos de la década de 1930 , el saldo de la cuenta «caja de aho-

20. En los casos del Hispano Americano y Español de Crédito, la consulta detenida de los estados mensuales de situación que figuraban en las actas elaboradas por cada respectivo Con- 
rros» de los bancos madrileños ya significaban más del $90 \%$ de lo contabilizado en toda la Zona Centro, y prácticamente la mitad del conjunto del país. A que esto fuera así contribuyó una evolución del ahorro más favorable, en parte por la condición de centro administrativo y en parte también por la progresiva apertura de sucursales en los principales núcleos urbanos del país.

Frente al mayor peso de la Zona Norte y el posterior empuje de la banca madrileña, cabe destacar también, como tercera observación, la delgadez que en la capacidad de captación de este tipo de excedente reflejó el conjunto de la banca radicada en Cataluña, particularmente en Barcelona y su provincia, y que contrasta también con los saldos mucho más positivos de los depósitos que contabilizaron los bancos radicados en Murcia, Baleares y, sobre todo, en Valencia y Zaragoza. Como ha argumentado Sudrià, las razones que lo explican venían de lejos. El resultado de las guerras coloniales de finales del siglo XIX había obligado a la industria catalana a emprender un doble camino: por un lado, acometiendo la búsqueda de nuevos mercados a la que la pérdida del mercado cubano urgía, sobre todo en lo que al textil se refería; y por otro, promoviendo nuevos sectores de inversión, tales como el metalúrgico y el eléctrico. Pero la estructura bancaria catalana mostró su incapacidad para responder a la demanda de crédito que las nuevas inversiones y reestructuraciones necesitaban para su desarrollo. Fruto de esta situación fue el progresivo control del mercado bancario catalán por entidades extranjeras y otros establecimientos que tenían su sede social fuera de esta región, principalmente en el País Vasco y en Madrid. ${ }^{21}$ A finales del último tercio del siglo $\mathrm{Xx}$, los bancos catalanes, que a comienzos de ese mismo siglo gestionaban más del $70 \%$ de los saldos de caja de ahorros del conjunto de la Zona Levante, apenas mantenían el umbral del 13\%; una cifra sensiblemente por debajo de la que ya reflejaba la banca radicada en Valencia $(28 \%)$ y, con más claridad, en Zaragoza (52\%). En Valencia, el interés por este recurso comenzó a ser asumido por el Banco Comercial Español (1907), que en 1927 fue adquirido por el Banco Español de Crédito, cuando ya el grueso de esta actividad recaía en el Banco de Valencia, que dos años después terminó controlando al Banco de Castellón (1922) y su importante caja de ahorros. En la plaza comercial de Zaragoza, el Banco de Aragón (1910) fue pionero en fijarse en este tipo de ahorro, al que siguió a partir de 1915 el Banco Zaragozano (1910) y el Banco Aragonés de Seguros y Crédito (1906) y, desde 1927, el veterano Banco de Crédito de Zaragoza (1875).

En la región de Murcia, el Banco de Cartagena (1900), antes de que en 1924 se refundara en Banco Internacional de Industria y Comercio, con sede

sejo de Administración sugiere que ya antes este tipo de ahorro fue atendido bajo la rúbrica de «cuentas de ahorro», que luego, en la publicación del Balance general anual, no afloraba al quedar agregado junto al resto de los depósitos suscritos a diversos plazos. Esta circunstancia también se detecta en la contabilidad de los bancos navarros (Crédito Navarro y La Vasconia).

21. Sudrià (1994). 


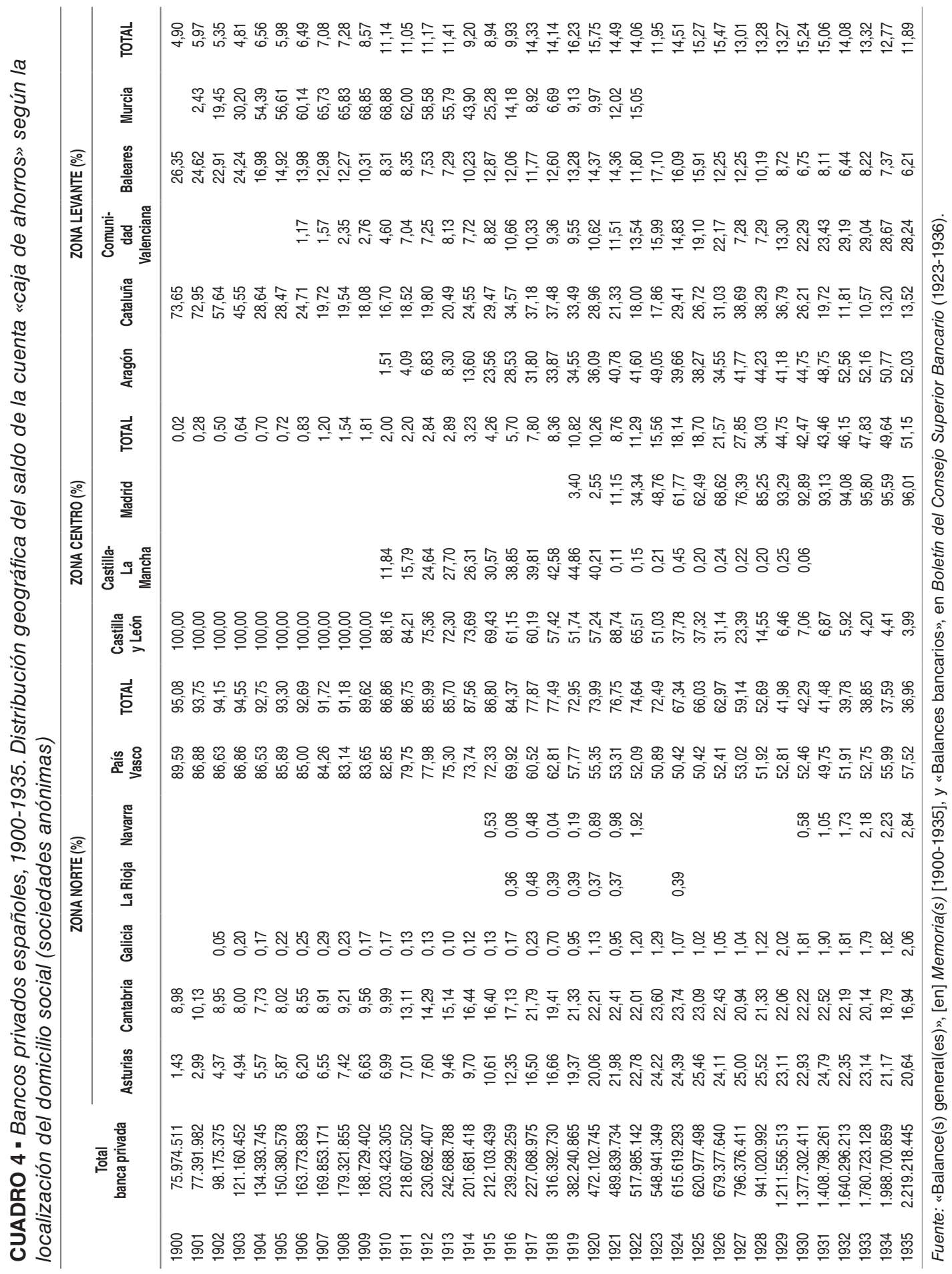


en Madrid, llegó a manejar remanentes muy importantes, que representaban en los años previos a la Primera Guerra Mundial más del 60\% de toda la zona bancaria. Y reseñable también fue cómo este tipo de ahorro se desenvolvió en Baleares, en virtud de una tupida red de pequeños establecimientos que acompañaron a entidades relativamente más grandes, como el Fomento Agrícola de Mallorca (1890), Banco Sóller (1890) y el Crédito Balear (1872); destacable porque en esta banca balear se dio la circunstancia de que el saldo en caja de ahorros fue predominante dentro del pasivo clientes. Es más, a lo largo de los años en que transcurrió la Primera Guerra Mundial, y en los cinco siguientes al fin de esta, su peso dentro de la zona bancaria en la que se inscribía se acercó bastante al que representó la banca catalana, e incluso llegó a ser superior a la valenciana.

La competencia con las cajas de ahorros benéficas en esta zona de Levante fue, asimismo, muy grande; sobre todo con la Caja de Pensiones para la Vejez y el Ahorro de Barcelona, que abarcaba con sus sucursales casi toda Cataluña y Baleares, y también con una pléyade de entidades que operaban en las más importantes agrociudades de las provincias de Zaragoza, Valencia, Alicante y Murcia, entre las que destacar la Caja de Ahorros y Monte de Piedad de Barcelona, la Caja de Ahorros de Valencia y la Caja de Ahorros y Monte de Piedad de Zaragoza.

El crecimiento del conjunto de los depósitos del pequeño ahorro se convirtió, en términos de su partición en el PIB, en un elemento relevante para la economía española del primer tercio del siglo. En el gráfico que se presenta a continuación se puede apreciar esta exponencial evolución. Si en 1900 apenas superaba el 2\%, en vísperas de la Primera Guerra Mundial este porcentaje ya se había duplicado, y se multiplicó casi por tres al año siguiente de haberse aprobado la Ley de Ordenación bancaria de 1921; el año en el que se proclamó la Segunda República, este tipo de depósito ya representaba poco más del 11\% del PIB y, en 1935, alcanzó el 14,14\%. Fue la constatación de esta progresión la que explica el porqué de la competencia entre cajas de ahorros benéficas y banca privada por este segmento del mercado financiero.

Como se ha dicho, las mejoras de los niveles de vida de las clases populares del país desde los inicios de siglo, especialmente en las zonas de rápida industrialización y de cambio agrícola, incrementaron sensiblemente la capacidad de ahorro. ${ }^{22}$ Esta circunstancia se tradujo en un aumento del número de cajas de ahorros benéficas, que pasaron de 50 entidades en 1900 a 133 en 1930, y de unos depósitos en la primera fecha de 179,2 millones de pesetas a

22. Véanse los trabajos de Pérez Castroviejo (2006); Martínez Soto, Pérez de Perceval y Martínez Pérez (2017); Maluquer de Motes y Llonch, M. (2005); Lana Berasain (2007) para el ámbito rural. 
GRÁFICO 8 - Participación porcentual del ahorro minorista en el PIB ${ }_{c f}$ del país 1900-1935 (cajas de ahorros, secciones cajas de ahorros de la banca privada y total)

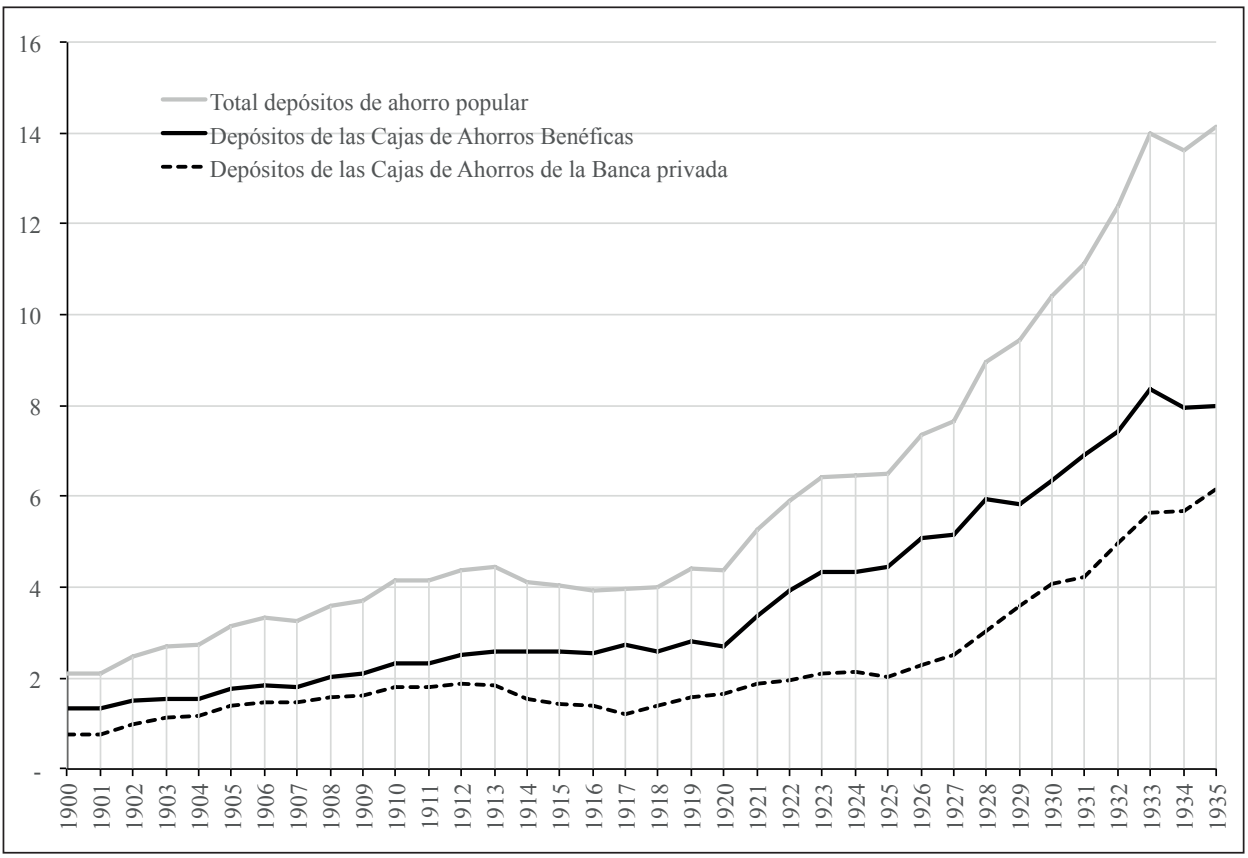

Fuente: Elaborado a partir de: para el PIBcf, Prados de la Escosura (2003), pp. 286-289. Para las cajas de ahorros benéficas: Martínez Soto y Cuevas Casaña (2004). Para las secciones de caja de ahorros de la banca privada: véase cuadro 3, «Nueva serie».

* Al total de los depósitos de las cajas de ahorros benéficas se ha añadido a partir de 1916 los saldos de ahorro de la Caja Postal.

3.976,5 millones de pesetas en 1935, con una tasa media de crecimiento anual del 9,26\%. ${ }^{23}$ También explica, como se ha señalado, el interés que este recurso fue despertando entre la banca privada. Sin embargo, este sector, a pesar de contar desde la década de 1920 con el apoyo del Consejo Superior Bancario y su influencia sobre el Ministerio de Hacienda, y a pesar también de su importante expansión por medio de absorciones y apertura de sucursales y agencias, no logró acaparar este segmento del mercado financiero. Como se observa en el gráfico 9, el sector de cajas de ahorro benéficas gestionó de media para todo el período el $61,6 \%$ de este tipo de depósito. Y lo más llamativo, en los años que siguieron a la aprobación de la Ley de Ordenación Bancaria de 1921, este porcentaje se incrementó hasta su máximo del $68,9 \%$ en 1926. A partir de ese año, las diferencias en cuota de participación fueron lentamente estrechándose. Con todo, en el año inmediatamente anterior al esta-

23. Martínez Soto y Cuevas Casaña (2004). 
GRÁFICO 9 - Cuotas del mercado minorista del ahorro de las cajas de ahorros benéficas $y$ de las secciones de cajas de ahorros de la banca privada, 1900-1935 (\%)

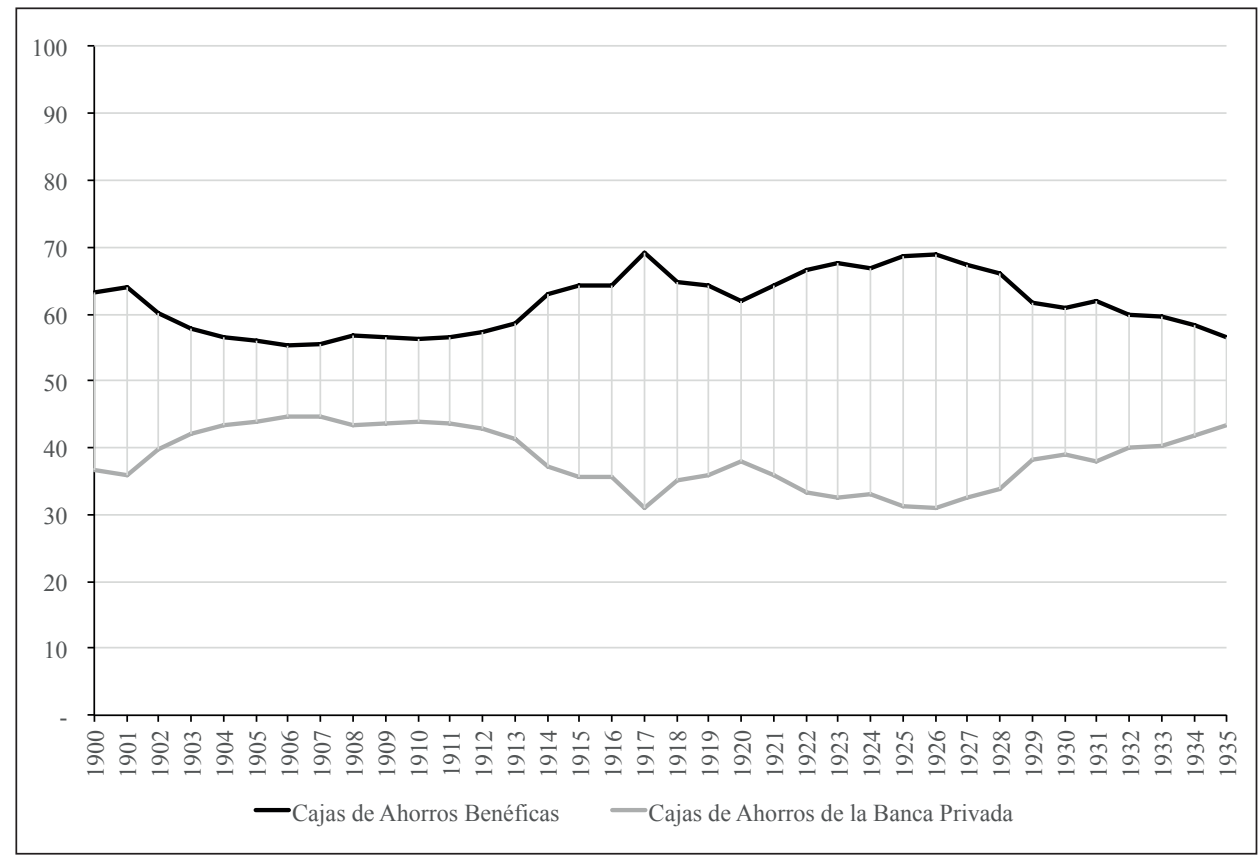

Fuente: Para las cajas de ahorros benéficas: Martínez Soto y Cuevas Casaña (2004). Para las secciones de caja de ahorros de la banca privada: véase cuadro 3, «Nueva serie».

llido de la Guerra Civil de 1936-1939, las cajas de ahorro benéficas aún representaban el 56,5\% dentro del mercado minorista del ahorro.

\section{Conclusiones}

A lo largo de todo el período aquí considerado, la captación del ahorro popular por parte de los bancos creció de forma exponencial, al adquirir un protagonismo creciente dentro del pasivo ajeno. Esta progresión fue particularmente intensa a lo largo del primer decenio del siglo Xx, sustentado en la mayor capacidad de ahorro que favoreció el auge finisecular y, a partir de 1923, por el impulso de las renovadas expectativas a que dio ocasión el nuevo ciclo expansivo de la economía. Este tipo de depósito bancario concernió e interesó, fundamentalmente, a un número muy importante de los bancos privados españoles. De entre estos, tuvo una mayor significación entre aquellos establecimientos cuyo mercado de actuación fue de alcance regional.

Desde el punto de vista de la distribución geográfica, es de reseñar que hasta finalizada la Primera Guerra Mundial, las regiones del norte fueron las 
principales receptoras y gestoras de ahorro popular; pero a partir de entonces lo más sobresaliente fue el fuerte impulso de la banca radicada en Madrid. Frente a este mayor peso de la Zona Norte y el posterior empuje de la banca madrileña, cabe destacar también la más exigua capacidad de captación de este tipo de recurso que reflejó la banca arraigada en Cataluña, que contrastaba llamativamente, dentro de esta Zona Levante, con los saldos mucho más positivos de los depósitos que contabilizaron los bancos asentados en Murcia, Baleares, Valencia y Zaragoza.

Desde los primeros años del siglo Xx, el sector de banca privada que operaba bajo la forma jurídica de sociedad anónima fue renovando profundamente sus estructuras; y ello en virtud de un doble y paralelo proceso de concentración por medio de la absorción de entidades menores y de expansión mediante la apertura de sucursales, ampliando el campo de sus operaciones hacia el ámbito de la promoción industrial y la búsqueda y captación de nuevas fuentes de recursos. Con este último propósito pusieron en práctica estrategias y productos para penetrar en el mercado minorista del ahorro que, hasta comienzos de siglo, acaparaban las cajas de ahorro benéficas y que cada vez resultaba más interesante por el volumen que iba alcanzando. Ello abrió un foco de colisión de intereses entre las cajas y las actividades de la banca privada en este sector minorista. Las primeras trataron desde el primer momento de hacer valer como propiedad el título de "caja de ahorro» y el de «libreta de ahorro», especialmente animadas por el Instituto Internacional del Ahorro, que en 1924 organizaba el Primer Congreso Internacional del Ahorro, celebrado en Milán, y donde se reivindicaron estos elementos como propios. ${ }^{24}$

La Ley de Ordenación Bancaria de 1921, que fijó la organización del Consejo Superior Bancario, generó la posibilidad para la banca privada de actuar como lobby de presión sobre el Gobierno y, especialmente, sobre el Ministerio de Hacienda. Esta corporación, a caballo entre la representación casi sindical de la banca y un medio oficial de organización del sector, trató, desde el mismo momento de su constitución, de limitar la operativa financiera de las cajas de ahorros benéficas, pretendiendo acabar con sus «privilegios» fiscales y abrir paso expedito a sus entidades «registradas» para que utilizasen el nombre de cajas de ahorros, cuentas y libretas de ahorro. Para ello contaban con ejemplos «históricos», con una larga trayectoria, como lo fueron las cajas de ahorros creadas por los bancos de Bilbao, Reus y Santander.

Las cajas de ahorro benéficas estuvieron bajo el patronato, en un primer momento, del Ministerio de Gobernación como entidades de beneficencia y, más tarde, del Ministerio de Trabajo (1926) como entidades de carácter social. En ambos casos, utilizando una especie de simbiosis por la que estas entidades financiaban acciones y políticas sociales públicas e invertían en deu-

24. Forniés (1989), pp. 23-24. 
da pública, recibían a cambio protección ante las presiones del poderoso Consejo Superior Bancario en su intención de que pasasen a depender del Ministerio de Hacienda y se recortase la mayor parte de la operativa que habían ido expandiendo en competencia con la banca privada: préstamos hipotecarios, préstamos personales, cuentas corrientes, imposiciones a plazos diversos. El primer aviso serio del Consejo Superior Bancario se produjo con el Real Decreto-Ley de 9 de abril de $1926,{ }^{25}$ pues las cajas benéficas se sintieron por primera vez víctimas de un complot para reducirlas a un papel residual dentro del sistema financiero. Esto hizo que rompiesen su aislamiento, constituyendo en 1928 la Confederación Española de Cajas de Ahorros Benéficas (CECAB), que pasó a ejercer la representación del sector ante las autoridades y actuar como el lobby de sus particulares intereses, confrontando con el Consejo Superior Bancario y buscando la estabilidad «perdida» por sus entidades afiliadas ante el acoso de la banca privada, que con su expansión territorial estaba en condiciones de plantar batalla por este tramo minorista de sector financiero.

\section{Bibliografía}

AA. VV. (2003). Ibercaja, una aportación al desarrollo económico y social, 1876.2001. Zaragoza: Ibercaja.

ARroyo Martín, J. V. (2003). La Banca en España en el período de entreguerras, 19201935. Un modelo de modernización y crecimiento. Bilbao: Fundación BBVA.

- (s/f). «Las Cajas de Ahorro en los mercados financieros del País Vasco, Navarra y La Rioja: características y su comportamiento expansivo entre 1940 y 1960». Disponible en: http://www.usc.es/estaticos/congresos/histec05/b8_arroyo.pdf.

Belford, N. (1979). «El Sistema bancario durante la Dictadura de Primo de Rivera». Cuadernos Económicos de ICE, n. ${ }^{\circ}$ 10, pp. 227-266.

Bernal Llorens, M. (2004). «Financial crises and the publication of the financial statements of banks in Spain, 1844-1868». Accounting Historians Journal 31, n. ${ }^{\circ} 2$, pp. 1-23.

Bernal Llorens, M; Sánchez Ballesta, J. P. (2007). «La información contable publicada por los bancos de emisión en España a mediados del siglo XIX». Revista Española de Financiación y Contabilidad, vol. 36, n. ${ }^{\circ}$ 133, enero-marzo, pp. 31-53.

- (2008). «Normalización contable de la banca española en los inicios de la industrialización». Revista de Historia Industrial, 36, año XVII, pp. 45-81.

- (2016). «Los bancos de emisión como empresas: resultados y situación patrimonial». En: Sudrià Triay, C.; Blasco-Martel, Y. (eds.), La pluralidad de emisión en España, 1844-1874. Madrid: Fundación BBVA, pp.111-139.

25. Gaceta de Madrid 16-04-1926, núm. 106, pp. 314-322. 
CArreras, A. (1999). «La coyuntura económica del 98». En: Ruiz MAnJón, O.; LANGA, A. (eds.), Los significados del 98. Madrid: Biblioteca Nueva.

Comín, F. (2007). «Spanish Savings Banks and the competitive cooperation model (19282002) ». Revista de Historia Económica. Journal of Iberian and Latin America Economic History, n. ${ }^{\circ}$ 2, pp. 199-229.

- (2008). Historia de la cooperación entre las Cajas. La Confederación Española de Cajas de Ahorro, 1928-2007. Madrid: Alianza.

- (2011). «Las cajas de ahorros: 1900-1975». En: Malo de Molina. J. L.; Martín ACEÑA, P. (eds.), Un siglo de historia del sistema financiero español. Madrid, Alianza, pp. 163-200

Emmons, W. R.; Schmid, F. A. (2000a). «Bank competition and concentration: Do Credit Unions matter?». Review, Federal Reserve Bank of St. Louis, mayo, pp. 29-42.

- (2000b). «Banks vs. Credit Unions: Dynamic competition in local markets, working paper 2000-006A». Review, Federal Reserve Bank of St. Louis.

Fornies CASAls, J. F. (1989). Las Cajas de Ahorros españolas en una etapa crucial de su historia, 1926-1939. Madrid: Confederación Española de Cajas de Ahorro.

Fundación de las Cajas de Ahorro (2005). Monográfico: «Historia de las Cajas de Ahorros. Nuevas perspectivas». Papeles de Economía Española, n. ${ }^{\circ}$ 105/106.

- (2003). Monográfico: «Los orígenes de las cajas de ahorro». Papeles de Economía Española, n. ${ }^{\circ} 97$.

García López, A. (1999). Una historia de la banca española a través de sus documentos. Valladolid: Lex Nova.

Gómez MendozA, A. (1997). «Del desastre a la modernización económica». En: Fusi, J. P.; NiÑo, A. (eds.), Vísperas del 98. Orígenes y antecedentes de la crisis del 98. Madrid: Biblioteca Nueva.

LANA BERASAIN, M. (2007). «El poder de compra de jornaleros y criados. Salarios reales y mercados de trabajo en la Navarra rural, 1781-1936». Investigaciones de Historia Económica, n. ${ }^{\circ}$, pp. 37-68.

MAiXÉ-Altés, J.C. (2010). «Competition and choice: banks and savings banks in Spain». Journal of Management History, vol. 16, n. ${ }^{\circ}$ 1, pp. 29-43. Disponible en: https://doi. org/10.1108/17511341011008296

MaiXé-Altés, J. C. (dir.); Vilar, M.; Lindoso, E. (2003). El ahorro de los gallegos. Orígenes e historia de Caixa Galicia (1876-2002). A Coruña: Fundación Caixa Galicia.

Maluquer de Motes, J. (2013). España en la economía mundial: Series largas para la economía española (1850-2015). Madrid: Instituto de Estudios Económicos.

Maluquer de Motes, J.; Llonch, M. (2005). «Trabajo y relaciones laborales». En: CARRERAS, A.; TAFUnell, X. (coords.), Estadísticas Históricas de España, siglos IX y XX. Bilbao: Fundación BBVA, pp.1156-1245.

Martín ACEÑA, P. (1985). «Desarrollo y modernización del sistema financiero, 18441935». En: SÁnchez-Albornoz, N. (eds.), La modernización económica de España, 1820-1930. Madrid: Alianza, pp. 121-146. 
- (2011). «La banca en España entre 1900 y 1975». En: Malo De MolinA, J. L.; MARTíN ACEÑA, P. (eds.), Un siglo de historia del sistema financiero español. Madrid: Alianza, pp. 117-161

Martín AceñA, P.; Nogués, P. (2013). «The Bank of Spain: A national financial institution». The Journal of European Economic History, n. ${ }^{\circ}$ 1, pp. 11-45.

Martín Aceña, P.; Pons, Ma A. (2005). «Sistema monetario y financiero». En: CARreRAS, A; TAFUnell, X. (coords.). Estadísticas históricas de España, siglos XIX y XX, Fundación BBVA, Bilbao, pp. 647-676.

Martínez Soto, A. P. (2000). «Las Cajas de ahorro españolas en el siglo Xix: entre la beneficencia y la integración en el sistema financiero». Revista de Historia Económica, año XVIII, n. ${ }^{\circ}$ 3, pp. 585-628.

- (2003). «Las Cajas de Ahorro españolas en el siglo XIX. Los orígenes del sistema (1839-1875)». Papeles de Economía Española, n. ${ }^{\circ}$ 97, pp. 174-302.

Martínez Soto, A. P.; Cuevas Casaña, J. (2004). «La expansión y consolidación de las Cajas de Ahorros en el sistema financiero española, 1880-1936». Revista de Historia Económica, año XXII, n. ${ }^{\circ}$ 1, pp.65-110.

Martínez Soto, A. P.; Cuevas, J.; Hoyo, A. (2005). «La historia económica de las Cajas de Ahorro españolas. Una perspectivas institucional y regional (2830-2004)». Papeles de Economía Española, n. ${ }^{\circ}$ 105/106, pp. 6-15.

Martínez Soto, A.P.; Pérez de Perceval, M.; Martínez Pérez, J. (2017). «Salarios y organización del trabajo en la minería del sureste español, 1850-1936». Revista de Historia Industrial, n. ${ }^{\circ}$ 69, pp. 49-79.

MuÑoz, J. (1978). «La expansión bancaria entre 1919 y 1926. La formación de una banca "nacional"», Cuadernos Económicos de ICE, n. ${ }^{\circ}$ 6, pp. 98-162.

Muñoz OrtegA, J. J. (1997). La Caja de Ahorros Municipal de Logroño (1893-1916). Beneficencia o financiación privilegiada del Ayuntamiento de Logroño, Logroño: Instituto de Estudios Riojanos.

NADAl, J.; Sudrià, C. (1983). Historia de la Caja de Pensiones. La Caixa dentro del sistema financiero catalán, Barcelona.

Nicolau, R. (2005). «Población, salud y actividad». En: Carreras, A.; TAFunell, X. (coords.), Estadísticas Históricas de España, siglos $I X$ y XX. Bilbao: Fundación BBVA, pp.77-154.

Pérez Castroviejo, P. M. (2006). «Poder adquisitivo y calidad de vida de los trabajadores vizcaínos, 1876-1936». Revista de Historia Industrial, año Xv, n. ${ }^{\circ}$ 30, I, pp. 103-142.

Pérez García, Ma P. (1991). La bancarrota de un banco emisor: el Banco de Valladolid. Madrid: Instituto de Contabilidad y Auditorías de Cuentas, Ministerio de Economía y Hacienda.

Prados de la Escosura, L. (2003). El progreso económico de España (1850-2000). Madrid: Fundación BBVA.

Puello SÁnchez, J. (2006). El comportamiento de la gran banca en España (1921-1974). Madrid: Banco de España, Estudios de Historia Económica, n. ${ }^{\circ} 48$. 
RocA, J. DE (1922). «La ficción del balance bancario único». Publicaciones de Actualidad Revista mensual de Hacienda, Banca, Industria, Comercio y Seguros, año II, n. ${ }^{\circ}$ 14, pp. $1-8$.

Roldán, S.; García Delgado, J. L. (1973). La formación de la sociedad capitalista en España, 1914-1920. Madrid: Confederación Española de Cajas de Ahorro, tomos I y II.

SAbaté Sort, M. (1996). El proteccionismo legitimado. Política arancelaria española a principios de siglo. Madrid: Civitas.

SudRiÀ, C. (1994). «Desarrollo industrial y subdesarrollo bancario en Cataluña». En: Hernández Andreu, J.; García Delgado, J. L. (comps.), Lecturas de historia empresarial. Madrid: Civitas, pp. 217-262.

Tedde, P. (1974). «La banca privada española durante la Restauración (1874-1914)». En: Tortella Casares, G. (dir.), La banca española en la Restauración. Madrid: Servicio de Estudios del Banco de España, tomo I, pp. 217-455.

Tedde, P.; Tortella, G. (1974). «Censo y balances normalizados de los bancos privados españoles (1874-1914». En: TorTella CASARES, G. (dir.), La banca española en la Restauración. Madrid: Servicio de Estudios del Banco de España, tomo II, pp. 212489.

Titos Martínez, M. (2003). El sistema financiero en Andalucía. Tres siglos de historia (1740-2000). Sevilla: Instituto de Estadística de Andalucía.

Tortella, G. (1975). Los orígenes del capitalismo en España. Madrid: Tecnos.

Tortella, G.; Palafox, J. (1983). «Banca e industria en España, 1918-1936». Investigaciones Económicas, n. ${ }^{\circ}$ 20, pp. 33-64.

VAldaliso, J. M. (2007). BBK (1907-2007). Cien años de compromiso con el desarrollo económico y el bienestar de Bizcaia. Bilbao: BBK. 


\section{The retail savings of Spanish private banking, 1900-1935}

ABSTRACT

The relative increase in wage income and, consequently, the improvement of living standards of the Spanish popular and middle classes between 1900 and 1935 led to an increase in their savings capacity. During these years the growth of savings balances generated a retail financial market that interested commercial banks, willing to enter into competition with charitable savings banks. The Ordinance Law of the Spanish banking system of 1921 and the creation of the Spanish Banking Control Council boosted interest in this competition to control retail savings. Commercial banks used the strategy of generating, within their organizations, "savings bank departments" that offered the savings products of the savings banks (charitable-social). In this paper we reconstruct the savings captured by commercial banks. It also analyses the structure of the client liabilities of the different types of commercial bank and banking areas.

KEYWORDS: savings, savings banks, commercial banking, savings bank departments, retail financial market

JEL CODES: Historia Económica; N, Mercados Financieros e Instituciones N2

\section{El ahorro minorista de la banca privada española, 1900-1935}

\section{RESUMEN}

El incremento relativo de los ingresos salariales y, en consecuencia, la mejora de los niveles de vida de las clases populares y medias del país entre 1900 y 1935 conllevó un incremento de su capacidad de ahorro. Durante estos años, el crecimiento de los saldos de ahorro generó un mercado financiero minorista que interesó a los bancos comerciales, dispuestos a entrar en competencia con las cajas de ahorros benéficas. La Ley de Ordenación del sistema bancario español de 1921 y la creación del Consejo Superior Bancario supusieron un refuerzo para los intereses de la banca en esta competencia por controlar el ahorro minorista. Los bancos comerciales utilizaron la estrategia de generar en su organización «secciones de caja de ahorros» que ofrecían los mismos productos de ahorro de las cajas de ahorros (benéfico-sociales). En este trabajo se reconstruye el ahorro captado por los bancos comerciales. También se analiza la estructura del pasivo clientes de los diferentes tipos de banca comercial y por zonas bancarias.

PALABRAS ClAVE: ahorro, cajas de ahorros, banca comercial, secciones de cajas de ahorros, mercado financiero minorista

Códigos JEL: Historia Económica; N, Mercados Financieros e Instituciones N2 